\title{
Surgical Management of Crohn Disease in Children: Guidelines From the Paediatric IBD Porto Group of ESPGHAN
}

\author{
*Jorge Amil-Dias, ${ }^{\dagger}$ Sanja Kolacek, ${ }^{\ddagger}$ Dan Turner, ${ }^{\S}$ Anders Porregaard, ${ }^{\text {Risto Rintala, }}$ \\ ${ }^{\top}$ Nadeem A. Afzal, " Katarzyna Karolewska-Bochenek, ** Jiri Bronsky, ${ }^{\dagger \dagger}$ Sonny Chong, ${ }^{\ddagger \dagger}$ John Fell, \\ ${ }^{\dagger}$ Iva Hojsak, ${ }^{\S}$ Jean-Pierre Hugot, ${ }^{|| l \mid}$ Sibylle Koletzko, "Tevinder Kumar, \\ ${ }^{\#}$ Izabella Lazowska-Przeorek, ${ }^{\# \#}$ Craig Lillehei, ${ }^{* * *}$ Paolo Lionetti, ${ }^{\dagger \dagger}$ Javier Martin-de-Carpi, \\ ${ }^{\|}$Mikko Pakarinen, ${ }^{\ddagger \ddagger}$ Frank M. Ruemmele, ${ }^{\S \S \S}$ Ron Shaoul, ${ }^{\prime \prime I||}$ Christine Spray,

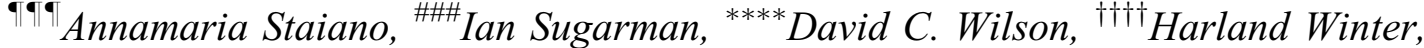 \\ and ${ }^{\ddagger \dagger \dagger \ddagger}$ Kaija-Leena Kolho, on behalf of the IBD Working Group of ESPGHAN (IBD Porto Group)
}

\begin{abstract}
The incidence of Crohn disease (CD) has been increasing and surgery needs to be contemplated in a substantial number of cases. The relevant advent of biological treatment has changed but not eliminated the need for surgery in many patients. Despite previous publications on the indications for surgery in $\mathrm{CD}$, there was a need for a comprehensive review of existing evidence on the role of elective surgery and options in pediatric patients affected with $\mathrm{CD}$. We present an expert opinion and critical review of the literature to provide evidence-based guidance to manage these patients. Indications, surgical options, risk factors, and medications in pre- and perioperative period are reviewed in the light of available evidence. Risks and benefits of surgical options are addressed. An algorithm is proposed for the management of postsurgery monitoring, timing for follow-up endoscopy, and treatment options.
\end{abstract}

Key Words: biologicals, complications, Crohn disease, inflammatory bowel disease, surgery, treatment

(JPGN 2017;64: 818-835)

Received February 13, 2017; accepted February 27, 2017.

From the *Department of Pediatrics, Centro Hospitalar, S. João, Porto, Portugal, the †Children's Hospital Zagreb, Faculty of Medicine, Zagreb, Croatia, the †The Juliet Keidan Institute of Pediatric Gastroenterology \& Nutrition, Shaare Zedek Medical Center, The Hebrew University of Jerusalem, Jerusalem, Israel, the $\S$ Department of Pediatrics, Hvidovre University Hospital, Hvidovre, Denmark, the $\mid$ Pediatric Surgery, Children's Hospital, University of Helsinki, Helsinki, Finland, the $\uparrow$ Department of Pediatric Gastroenterology, University Hospital Southampton, Southampton, UK, the \#Department of Pediatric Gastroenterology and Nutrition, Medical University of Warsaw, Warsaw, Poland, the **Department of Pediatrics, University Hospital Motol, Prague, Czech Republic, the ††Queen Mary's Hospital for Children, Epsom and St Helier NHS Trust, Surrey, the $¥$ Chelsea and Westminster Hospital, London, UK, the §§ParisDiderot Sorbonne-Paris-Cité University and Robert Debré Hospital, Paris, France, the |||| Pediatric Gastroenterology and Hepatology, Dr. von Hauner Children's Hospital, Ludwig Maximilians-University, Munich, Germany, the $\uparrow$ St George's, University of London, London, UK, the \#\#Boston Children's Hospital and Harvard Medical School, Boston, MA, the $* * *$ Department NEUROFARBA, University of Florence - Meyer Hospital, Florence, Italy, the †††Unit for the Comprehensive Care of Pediatric Inflammatory Bowel Disease, Hospital Sant Joan de Déu, Barcelona, Spain, the $\ddagger \ddagger$ Department of Pediatric Gastroenterology, Necker Enfants Malades University Hospital, Sorbonne Paris Cité University, Paris Descartes University, Institut IMAGINE - INSERM U1163, Paris, France, the

\section{INTRODUCTION AND AIMS}

$\mathrm{T}$ he incidence of pediatric Crohn disease (CD), particularly in children 10 to 19 years of age, is increasing and the phenotype is often characterized by extensive inflammation and an aggressive and progressive disease course including growth failure (1-6). Despite optimized treatment, almost one-third of the patients will have complications such as fistulae, strictures, and abscesses, undergoing invasive treatment within 5 years of diagnosis $(7,8)$. Furthermore, the risk of having surgery is several times higher in children with a long-standing disease than in adults. The risk of surgery at the age of 30 for patients with onset of CD in childhood is $48 \pm 5 \%$ compared with $14 \pm 2 \%$ for patients with adult-onset CD (9).

Surgical procedures in patients with CD can be categorized into 3 major groups: ileocecal resections performed to achieve remission, treatment of complications such as fistulae with or without abscess formation and strictures, and salvage procedures

$\S \S \S$ Pediatric Gastroenterology Institute, Ruth Children's Hospital, Rambam Medical Center, Haifa, Israel, the |||||||Department of Pediatric Gastroenterology, Bristol Royal Hospital for Children, Bristol, UK, the - ๆDepartment of Translational Medical Science, Section of Pediatrics, University of Naples "Federico II," Naples, Italy, the \#\#Department of Pediatric Surgery, Leeds Children's Hospital, Leeds General Infirmary, Leeds, UK, the $* * * *$ Child Life and Health, University of Edinburgh, Scotland, UK, the It††MassGeneral Hospital for Children, Harvard

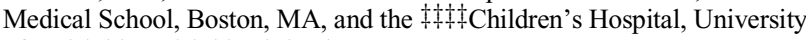
of Helsinki, Helsinki, Finland.

Address correspondence and reprint requests to Jorge Amil-Dias, Centro Hospitalar S. João, P-4202-451 Porto, Portugal (e-mail: jamildias@ zonmail.pt).

Supplemental digital content is available for this article. Direct URL citations appear in the printed text, and links to the digital files are provided in the HTML text of this article on the journal's Web site (www.jpgn.org).

ESPGHAN is not responsible for the practices of physicians and provides guidelines and position papers as indicators of best practice only. Diagnosis and treatment is at the discretion of physicians.

The authors report no conflicts of interest.

Copyright (c) 2017 by European Society for Pediatric Gastroenterology, Hepatology, and Nutrition and North American Society for Pediatric Gastroenterology, Hepatology, and Nutrition

DOI: 10.1097/MPG.0000000000001562 
such as subtotal colectomy (eg, proctocolectomy) for severe refractory colitis or small bowel resection for refractory jejuno/ileitis (10). Urgent surgical procedures related to peritonitis or abdominal abcesses are beyond the scope of this document and will not be addressed.

The most recent pediatric European Crohn's and Colitis Organization (ECCO)/European Society for Pediatric Gastroenterology, Hepatology, and Nutrition (ESPGHAN) guidelines provide guidance for medical, but not for surgical treatment of CD (11). The role of surgery in children with $\mathrm{CD}$, especially with respect to elective resection of medically resistant localized disease, has been addressed in the 1st and the 2nd European evidence-based consensus guidelines $(12,13)$. The present report is based on expert opinion and a critical review of the literature and is intended to provide evidence-based guidance for surgical management of pediatric patients with $\mathrm{CD}$, including the role of elective surgery in not only achieving and maintaining remission, but also treating complications and managing pre- and postoperative care. The objectives are to clarify indications as well as delineate risks and benefits of surgery taking into consideration the needs of the individual patient, the natural history of the disease, and currently available alternative medical treatment options.

\section{METHODOLOGY}

\section{Selection of the Authors and the Relevant Clinical Topics}

The development of these guidelines was initiated at the annual meeting of the ESPGHAN IBD Working Group in Porto in the year 2013, and was followed by an open call to Working Group members. To obtain a balanced position, several other experts joined, including pediatric surgeons. Five major topics were addressed by independent working groups:

a. Indications for surgery in pediatric CD

b. Consideration for and type of surgery

c. Pre- and postoperative care

d. Risks associated with surgery as it relates to the natural history of disease

e. Surgical management of perianal disease

\section{Literature Search, Grading of the Evidence, Consensus Strategy}

The authors of the Working groups performed a systematic literature search using MEDLINE-Pubmed, Embase, CINAHL, and the Cochrane Library with the last search date of 2015. Because evidence-based reports on surgical procedures in children with CD are limited, the review included data in adults. The limited pediatric literature precluded the use of the Oxford grading.

Proposed recommendations and practice points were discussed during the 2 face-to-face meetings and anonymous voting. Where the pediatric literature was sparse, recommendations were based on adult data. Controversial issues or recommendations in the absence of relevant pediatric data were resolved by consensus. Final recommendations were accepted when at least $80 \%$ agreement was achieved.

\section{EPIDEMIOLOGY OF SURGERY FOR PEDIATRIC CROHN DISEASE}

The natural history of pediatric $\mathrm{CD}$, including need for surgery, is based mainly on cohort studies. Early case series and cohorts from the 1970s and 1980s reflected the lack of effective medications in pediatric-onset inflammatory bowel disease (IBD) to maintain remission $(14,15)$.
As a result of the increasing use of immunomodulators and biological anti-tumor necrosis factor (TNF) $\alpha$ agents, such as infliximab (IFX) and adalimumab (ADA) introduced during the past 15 years to both induce and maintain remission in chronically active $\mathrm{CD}$, the rate of surgical management of pediatric $\mathrm{CD}$ may have changed. In pediatric clinical practice, the availability of anti-TNF $\alpha$ agents has differed among regions and countries. These medications approved rapidly in North America (16) and parts of Europe (eg, Denmark (17), the Netherlands (18), and France (19)) as they were able to use adult data to prescribe them. In the United Kingdom, for example, evidence from randomized controlled trials (RCTs) in children (20-22) were required before approval was given, and in much of eastern Europe availability of anti-TNF agents to treat children with $\mathrm{CD}$ came much later. For these reasons, the natural history is evolving, with systematic reviews showing reduced surgical rates in adult $\mathrm{CD}$ with increased use of thiopurines and IFX $(23,24)$. In contrast, limited evidence in pediatric CD from either case series or population-based cohort studies suggest lower surgical rates when $25 \%$ of patients receive anti-TNF $\alpha$ medications for $\mathrm{CD}$ versus earlier periods in the same region when patients were not treated with these medications $(19,25,26)$. The level of exposure to immunomodulators and anti-TNF $\alpha$ agents during the period of assessment is critical in determining its impact on natural history of CD. Finally, when looking for evidence to evaluate the risk of surgical resection or postresection recurrence in children with $\mathrm{CD}$, most information is obtained from series of primarily adult patients that include small numbers of pediatric patients with $\operatorname{CD}(27,28)$.

As case series of surgery for pediatric $C D$ have been published primarily from single academic centers, rather than population-based cohorts, there is a possibility of bias based upon referral, increased severity of $\mathrm{CD}$, or more access to anti-TNF $\alpha$ therapy $(14,15,19,25,26,29-31)$. Although longitudinal pediatric $\mathrm{CD}$ data from Europe and Canada suggest decreasing rates of CD surgery with time, the reverse has been described in the United States $(8,25,32,33)$. When pediatric-onset $\mathrm{CD}$ was compared with adult-onset $\mathrm{CD}$ in the same Scottish population, the rate of surgery at 10 years follow-up and median time to first surgical resection were lower (35\% vs 56\%) and longer (13.7 vs 7.8 years), respectively (34). Recent reports show that recurrence rate seems to be high in children: for example, the French Registry of Inflammatory Bowel Diseases incident cohort from Northern France reported CD resection rates of $7 \%$ of pediatric patients at 1 year, $20 \%$ at 3 years and $34 \%$ at 5 years (8). Further follow-up of the 404 pediatric CD cases diagnosed between 1988 and 2004 in the French Registry of Inflammatory Bowel Diseases cohort noted a recurrence rate of $29 \%$ in 140 patients 10 years after their first resection (35). Smoking, prior resections, perianal disease, penetrating disease behavior and extensive $(>50 \mathrm{~cm})$ small bowel resection have been identified as risk factors for postoperative recurrence in mainly adult-onset $\mathrm{CD}$. The relevance of serology and CD genotype are not known, and there are no unequivocal, confirmed risk factors for post-operative recurrence in the current pediatric literature (27), but stricturing and penetrating $\mathrm{CD}$ at diagnosis are associated with an increased risk for a second resection (36).

\section{CONSIDERATIONS FOR SURGERY IN PEDIATRIC CROHN DISEASE}

\section{Definition of a Refractory Crohn Disease Patient}

A patient is considered to be refractory to given treatment options when his/her signs and symptoms are caused by CD, relapse during optimized maintenance therapy (immunomodulators, anti$\mathrm{TNF} \alpha$ agents or other biologicals released for pediatric $\mathrm{CD}$ ) and do not sufficiently respond to induction therapy (corticosteroids, 
Exclusive Enteral Nutrition-EEN) in spite of being on maintenance therapy. Nonadherence, insufficient therapy, and other causes for the signs and symptoms should be excluded before surgery is considered.

It is mandatory to prove with a high degree of certainty that signs and symptoms are due to active $\mathrm{CD}$ and not due to other causes (eg, diarrhea due to bile salt loss or infection, abdominal pain due to functional disorders or depression, growth failure due to growth hormone or nutritional deficiencies). Alternatively, if a specific bowel segment is responsible for symptoms, surgical intervention may be more appropriate than continued medical treatment. Nonadherence, inadequate dosing, or duration of medical therapy must be considered, before the patient is deemed to be refractory to therapy. Some relevant issues that should be considered before surgical intervention are shown in Table 1 .

The decision for or against elective surgery in a patient with refractory $\mathrm{CD}$ rests on the short-term and long-term risks and benefits, such as the extent of disease and likelihood of remission or recurrence with resection. The decision is highly individualized.

Surgical resection is not curative for CD. Relapse, both at the area of anastomosis and at other sites, frequently occurs within 5 years postsurgery $(31,37,38)$. Refractory disease implies that the defined treatment goal for this patient cannot be achieved with the nonsurgical treatment option(s) and/or that continued medical management may have higher short-term or long-term risks than surgery. One must also take into account the relative costs and potential toxicities of long-term medical therapy. Treatment goals differ from patient to patient and should be well defined when a surgical procedure is considered. They include improvement of signs and symptoms severely affecting the quality of life (eg, pain, diarrhea, obstruction, fecal incontinence, growth failure) or prevention of severe complications (eg, ileus in bowel occlusion, fistula, abscess formation).

\section{Indications for Surgery}

Statement 1. Surgery may be considered as an alternative to medical therapy when a patient has active disease limited to a short segment(s) despite optimized medical treatment. (Agreement 100\%)

Statement 2. Surgery should be considered in children in prepubertal or pubertal stage if growth velocity for bone age is reduced over a period of 6 to 12 months in spite of optimized medical and nutritional therapy. (Agreement $100 \%)$

\section{Practice points:}

1. In the absence of refractory disease, elective surgery is usually not indicated.

2. In prepubertal or pubertal children with a delay in bone age, resection of a localized disease segment that is resistant to conservative therapy, may lead to catch-up growth within the next 6 months of postoperative period.

Growth failure is more frequent in $\mathrm{CD}$ than in ulcerative colitis (UC) being present in $15 \%$ to $40 \%$ of pediatric CD patients $(39,40)$. Although the use of corticosteroids has been implicated in growth failure, uncontrolled disease activity is considered the major factor. One of the main contributors to growth impairment is malnutrition influenced by enteric losses with malabsorption, suboptimal intake and increased energy needs (41). Moreover,
TABLE 1. Issues to consider before surgical intervention

\begin{tabular}{lc}
\hline Item & Features to consider \\
\hline CD phenotype & $\begin{array}{c}\text { Paris classification: distribution, structuring or } \\
\text { inflammatory or both, presence and location of } \\
\text { fistula }\end{array}$ \\
$\begin{array}{l}\text { Disease severity } \\
\text { In case of strictures }\end{array}$ & $\begin{array}{c}\text { Length, degree, and particular location of the } \\
\text { stricture (eg, a short stricture in the proximal } \\
\text { duodenum versus the same stricture in the }\end{array}$ \\
& small or large bowel) \\
In case of fistula & or multiple, location (starting and ending point) \\
Current drug & Compliance? Previous and current response? Do \\
treatment & they increase the risk of complications and \\
& should be discontinued or decreased? \\
Previous drug & Reason for discontinuation: Loss of response? \\
treatment & Nonadherence? Side-effects? \\
Previous EEN & Compliance, response and duration of remission \\
Growth potential & Age, pubertal status, bone age, height for age, \\
& and growth velocity over the last 6 (-12) \\
Nutritional status & months \\
& BMI, deficiencies of micronutrients affecting the \\
Comorbidities & immune system and healing process \\
Other chronic disease? Infections? Primary & immunodeficiency disease excluded? \\
Competence of the & P-IBD competent center? \\
treating center &
\end{tabular}

$\mathrm{BMI}=$ bone mass index $; \mathrm{CD}=$ Crohn disease $; \mathrm{EEN}=$ exclusive enteral nutrition; $\mathrm{P}-\mathrm{IBD}=$ pediatric-onset IBD.

increased cytokine production [eg, interleukine (IL)-1 $\beta$, IL-6, $\mathrm{TNF} \alpha$ ], impairs hepatic expression of insulin-like growth factor 1 and contributes to growth hormone resistance in chondrocytes. Growth failure, characterized by delayed skeletal maturation and delayed onset of puberty, is best described in terms of height-forage standard deviation score ( $z$ score) or by variations in growth velocity for a period of 6 to 12 months. Earlier literature described the role of surgery in promoting growth in $\mathrm{CD}$ pediatric patients $(42,43)$. Most of these studies, however, were performed before the era of biological agents and may have been impacted by the increased use of corticosteroids.

Three retrospective trials with growth as an outcome measure were identified. One of these evaluated the effect of surgery on growth in children with $\mathrm{CD}$ who did not respond to medical therapy (30). Growth and nutritional status improved by 6 and 12 months after surgery, with a significant increase in weight and height $z$ scores. The other 2 studies analyzed the postoperative course of pediatric $\mathrm{CD}$ and the predictive factors of early postoperative recurrence $(44,45)$. After surgery, a significant improvement occurred in $z$ scores for height and a mean height velocity of patients increased from $2.3 \mathrm{~cm} / \mathrm{y}$ preoperatively to $3.4 \mathrm{~cm} / \mathrm{y}$ following surgery. These results were supported by other studies (46-49). Moreover, delaying surgical intervention into the late stages of puberty results in poor catch-up growth (39).

Furthermore, concerns about inadequate growth and the prospect of not achieving adult growth potential may impact the quality of life for some patients. For these reasons, surgery should be considered a therapeutic strategy for inducing remission in early or mid-puberty in a child with localized CD who is refractory to medical therapies. Refusal, intolerance, or increased risks of maintenance medications such as immunomodulators or anti-TNF $\alpha$ agents may also be considered as possible indications for elective surgery. 


\section{Investigations Required Before Surgery}

Statement 3. A complete assessment of the patient's general and bowel condition is recommended before elective surgery to optimize the surgical approach, minimize the length of bowel resection, and reduce the risk of complications. It should include history, physical examination, ileocolonoscopy, imaging studies, screening for concomitant infections, and nutritional deficiencies. (Agreement $100 \%)$

\section{Practice points:}

1. The optimal timing of surgery, the approach (laparoscopic or open) and bowel segments to be addressed should be discussed among the pediatric gastroenterologist, pediatric (or adult) surgeon, patient, and parents.

2. It is preferable that ileocolonoscopy (eosophagogastroduodenoscopy being optional depending on the actual disease) and imaging studies are performed in the center where the surgery will be performed.

3. The nutritional status should be assessed by anthropometry, laboratory parameters such as albumin, iron status, and selected vitamins and trace elements, depending on the individual patient.

4. In severe cases an extensive workup for immunodeficiency disorders should be completed in a specialized center before surgery.

\section{SELECTION OF THE TYPE OF SURGERY}

Statement 4. Limited resection should be performed when a patient has localized small bowel or colonic CD not responsive to medical therapy. (Agreement 100\%)

Statement 5. Stricturoplasty needs to be considered when a symptomatic patient has multiple short strictures in the small bowel. (Agreement 100\%)

Statement 6. Extensive resections of the small bowel should be avoided as they pose a long-term risk of development of short-bowel syndrome. (Agreement 100\%)

Statement 7. When a patient has pancolonic disease the choice of surgery is subtotal colectomy and ileostomy. Later ileorectal anastomosis can be performed if rectum is spared and there is no significant perianal disease. One stage ileo-rectal anastomosis is generally not advised. (Agreement 100\%)

Statement 8. Ileal pouch-anal anastomosis is not recommended when a patient has CD. (Agreement 100\%)

\section{Practice points:}

1. Limited resections are especially relevant for ileocecal lesions.

2. Although stoma is recommended as a general rule, partial colectomy and ileo-rectal anastomosis may be performed without diverting ileostomy as a primary procedure in patients without significant immunosuppression or malnutrition. Increased rates of leakage associated with ileo-rectal anastomoses, however, support the use of temporary diverting ileostomy (44).

3. Reversal of the diverting ileostomy following colonic resection may result in recurrence of inflammation in the colon or rectum.
4. Patients requiring emergent colectomy are not candidates for immediate reconstruction and should undergo a 2- or 3-staged procedure.

5. Although not recommended as a standard procedure, ileal pouch anal anastomosis may be considered in highly selected cases, that is, these patients need to be highly motivated and have no perianal or small bowel disease and good sphincter function. Successful outcomes can be achieved with this procedure.

6. Patients and their families should be aware of all possible risks and high complication rate including anastomotic leaks, anastomotic strictures, fistula formation to the anastomosis, as well as the risk of recurrence. Significant time should be dedicated to patients and their families during the counseling before the surgical procedure to discuss the possible complications and functional impairment.

\section{Limited Small Bowel Disease}

For single site disease, such as the ileocecal area, a limited resection may be the treatment of choice. Reports of isolated small bowel resection surgery can be found in many of the larger published pediatric surgical series ( 1 case each described by Romeo et al (50), Simon et al (51) and 2 cases each by Ba'ath (52), Blackburn et al (31), 11 cases by Hansen et al (38), 16 cases by Diamond et al (29)). There is considerable debate in the literature whether surgery for $\mathrm{CD}$ should be performed laparoscopically or through the conventional open technique (53-55). The laparoscopic surgical approaches, however, can certainly be used safely in children with low complication rates $(29,55-57)$.

For single and multiple site disease, stricturoplasty is best undertaken to preserve bowel length. Stricturoplasty has the advantage of bowel preservation, whereas surgical resection may put the patient at risk for short bowel. There does not appear to be a significant difference between the outcomes or the complication rates between surgical resection or stricturoplasty in pediatric $C D$ (50).

Standard Heinecke-Miculicz stricturoplasty is suitable for short segment strictures. Finney type stricturoplasty is used for strictures up to $20 \mathrm{~cm}$ long. For longer than $20 \mathrm{~cm}$ strictures, either a specialized form of stricturoplasty or a combination of resection and stricturoplasty type with anastomosis may be used.

\section{Colonic Crohn Disease}

Symptoms of colitis are typically the first manifestations of $\mathrm{CD}$ in children under the age of 8 years $(58,59)$. The distribution of the disease may change with age making the choice of most appropriate surgery more difficult (59). There is a lack of reliable pediatric data related to the management of Crohn colitis.

The main problem in the choice of operative treatment for colonic $\mathrm{CD}$ is the expected high rate of disease relapse $(37,44)$. Due to the high incidence of complications and relapses, risk of pediatric patients with colonic disease to end up with permanent ileostomy has been considerable. Recent reports in adults suggest that bowel sparing surgery in the form of segmental resections has better longterm outcomes $(60,61)$. Segmental large bowel resections have also been performed in children with left-sided colitis (62) but recent data in 81 patients suggested that most patients will eventually require subsequent colectomy (Ian Sugarman, personal communication). Harper showed that temporary ileostomy is a safe conservative procedure which enables improvement in severely ill and even malnourished patients with Crohn colitis (63). When a subsequent resection becomes necessary, it may be less extensive than 
initially considered because of the healing that has occurred due to improved nutrition (64). Long-term remission is more common in patients with no significant anorectal disease (65). Female gender and history of perianal disease have been reported to be predictive of repeat resection (61). An important technical detail is to perform a wide bowel anastomosis, preferably with a stapled functional endto-end technique that is associated with longer recurrence-free periods when compared with hand sewn anastomoses (66).

In children with refractory pan-colonic disease the choice of operation is usually total colectomy and ileo-rectal anastomosis. Elective resection with a primary anastomosis may be considered in a stable patient with good nutritional status. In the case of an emergency the best choice is, however, usually a staged procedure. Patients undergoing ileo-rectal anastomosis have excellent chances to avoid protectomy and permanent stoma formation. Preservation of the ileo-rectal anastomosis despite frequent recurrences of active disease has been reported in $76 \%$ to $86 \%$ of the cases $(67,68)$. Active anorectal disease at the time of the anastomosis is the best predictor for failure of the anastomosis (68).

An alternative for total colectomy and ileo-rectal anastomosis is ileal pouch-rectal anastomosis. This may be considered in cases in which only a short segment of the rectum is retained following resection of diseased large bowel. A short ileal pouch (8$10 \mathrm{~cm}$ ) is anastomosed with the rectal stump. The outcomes after ileal pouch-rectal anastomosis are similar to those after ileo-rectal anastomosis (69).

Ileal pouch-anal anastomosis is generally thought to be contraindicated in CD (70). This is based on data from patients having undergone ileal pouch-anal anastomosis for presumed UC who subsequently had a change of diagnosis to $\mathrm{CD}$. The cumulative frequencies of $\mathrm{CD}$ of the ileo-anal pouch originally devised for UC has ranged between $3 \%$ and $13 \%$ (71). The diagnosis of $\mathrm{CD}$ of the pouch has been associated with 5 -fold increase in risk of pouch failure compared with patients with ileo-anal pouch without $\mathrm{CD}$ $(72,73)$.

There is, however, recent growing evidence that supports highly selective use of restorative proctocolectomy with ileal pouch-anal anastomosis for $\mathrm{CD}$. These patients have isolated colonic $\mathrm{CD}$ and no evidence of ileal or perianal involvement.

In patients with severe rectal and perianal disease, proctectomy or enteric diversion are rarely indicated, see section of Perianal disease. Colonic stricturoplasties, although feasible, are associated with a higher risk of complications and are therefore seldom used.

\section{RISK FACTORS OF COMPLICATIONS OF SURGERY AND PERIOPERATIVE MANAGEMENT \\ Immediate Postoperative Complications}

Statement 9. Corticosteroids exposure should be minimized prior surgery to reduce surgery-related complications such as infections. (Agreement 100\%)

Statement 10. Anti-TNF $\alpha$ administration during immediate perioperative period (see practice point) is discouraged, as it is associated with an increased risk of infection. (Agreement 100\%)

Statement 11. Nutritional status should be optimized and anemia corrected to reduce the risk of postoperative complications. (Agreement 100\%)

Statement 12. A patient should cease smoking before surgery given the strong association of smoking with postoperative recurrence. (Agreement 100\%)
Practice points:

1. Risk factors of perioperative complications include poor nutritional status, anemia, cigarette smoking and perioperative corticosteroid or anti-TNF $\alpha$ treatment.

2. Immediate postoperative morbidity ranges from $20 \%$ to $30 \%$, in small bowel or ileocolic resection to $50 \%$ to $60 \%$, in subtotal colectomy $(29,74,75)$.

3. Whenever possible, it is recommended to discontinue corticosteroids before surgery or to lower the dose to at least $0.5 \mathrm{mg} / \mathrm{kg}$ or $20 \mathrm{mg}$, whatever is less to minimize the risk of complications.

4. It is advisable to avoid anti-TNF drugs during the perioperative period (optimally $4-6$ weeks before and in high-risk patients continuing anti-TNF postoperatively $1-3$ weeks following surgery to minimize the risk of complications and in the latter group the risk of development of drug antibodies).

5. Data on the impact of immunomodulators to the risk of immediate postoperative complications is limited and conflicting. Although immunomodulators may be used throughout the perioperative period if maintenance therapy is indicated postoperatively, it may be reasonable to discontinue treatment with immunomodulators at least 1 week before surgery to reduce the risk for infections.

6. Stress doses of corticosteroids should be administered if steroids are ongoing or discontinued close to the time of the surgery, or adrenal suppression is not excluded.

7. Nutritional status should be optimized before surgery by using enteral nutrition (EN), but for some patients TPN may be needed.

8. Bowel cleansing is performed at discretion of the surgeon but not routinely required.

9. Although infrequent, the presence of hyperglycemia should be excluded, as it is associated with poorer outcomes, including poor wound healing and increased risk of infection.

10. Hospitalized children with CD should be assessed for potential risk factors for venous thromboembolism (VTE) including disease activity, steroid use, central venous access, parenteral nutrition, hypercoagulable condition, and immobilization. VTE prevention such as hydration, compression stockings, and mobilization should be provided to all patients. Pharmacological thromboprophylaxis may be considered in the postoperative course, although the absolute risk of VTE in children appears lower than in adults.

11. If indicated by family history, common genetic mutations associated with an increased risk of VTE should be screened preoperatively.

The most common short-term postoperative complications of bowel surgery are anastomotic leak, small bowel obstruction and ileus, infections, need for ileostomy, wound complications, fistulas, gastrointestinal bleeding, and VTE. Complication rates seem to be slightly lower in children than in adults, but vary a lot between procedures and studies $(31,76-78)$. Cigarette smoking is associated with an increased risk of postoperative complications in adults (odds ratio $[\mathrm{OR}]=1.24(1.09-1.41)$ with $\mathrm{CD}$ (79). Anemia and weight loss before surgery are also associated with a worse prognosis (79). Blackburn et al (31) recently reported their 10-year pediatric experience on risk of complications at a regional pediatric gastroenterology center. Among the 62 patients, there were 13 $(22 \%)$ early and $5(8.6 \%)$ late complications following intraabdominal surgery. Piekkala et al (37) reported their long-term surgical outcomes in 36 Finnish children. At least 1 surgical 
complication occurred in $77 \%$ of patients. In a recent study, the postoperative complication rate was significantly lower in patients who had an ileal $1 / 16(6 \%)$ or ileo-cecal resection $13 / 54(24 \%)$ compared with hemi- 5/12 (42\%) or total colectomy 11/21 (52\%). In this report $10 \%$ to $30 \%$ of patients required further intervention mainly for ileus, bleeding, and infection (38).

In children, the absolute risk of VTE is lower than in adults $(80,81)$. The absolute risks for VTE among children with CD with and without surgery were calculated to be 111.2 and 121.2/10,000 hospitalizations, respectively (80). There are no published trials for the efficacy and safety of thromboprophylaxis in children with CD, but a guideline for evaluation of risk and prophylactic options has been proposed (82).

\section{Perioperative Medication \\ Corticosteroids}

In adults, most publications have reported a negative impact of the preoperative use of $\geq 5 \mathrm{mg}$ prednisone (or its equivalent) daily within 14 to 60 days before surgery or $\geq 10 \mathrm{mg}$ prednisone (or its equivalent) for at least 4 weeks before surgery $(83,84)$. In their prospective follow-up study, Nguyen et al (85) reported an excess of complications, but not mortality, in patients with corticosteroid use within 30 days before surgery (adjusted OR (95\% confidence interval $[\mathrm{CI}])=1.26(1.12-1.41)$ for $\mathrm{CD}$. In the long-term registry of North American patients with Crohn Disease (TREAT) registry glucocorticoid use was an independent risk factor of serious infections (OR, 2.21; 95\% CI, 1.46-3.34) (86,87). In addition to the septic concerns, steroid use can lead to the suppression of the hypothalamus-pituitary-axis and subsequent adrenal insufficiency, even after shorter periods of therapy $(84,88,89)$. For this reason, perioperative glucocorticoid replacement therapy may be required. Wound healing complications, such as, disruption, persistent drainage, dehiscence, or wound failure, are usually associated with chronic use of corticosteroids at high doses (90).

\section{Aminosalicylates}

There is a paucity of clinical data for perioperative use of 5 aminosalicylates (5-ASA). Kumar et al (91) suggested to discontinue the drug on the day of surgery. Continuing drugs after surgery is specific to each patient.

\section{Immunomodulators}

There are conflicting reports about the use of immunomodulators preoperatively and most data comes from adult studies (84). In a retrospective study of $159 \mathrm{CD}$ patients undergoing bowel surgery, Aberra et al (92) found no increased infectious risk among patients receiving corticosteroids alone or patients receiving thiopurines with or without corticosteroids, in comparison to patients receiving neither medications. Additional reports including $>200$ adult patients each identified no increased risk of complications with immunosuppressive therapy at surgery $(93,94)$. Tay et al $(95)$ reported a lower incidence of septic complications in patients receiving immunomodulators $(5.6 \%$ vs 25\%). In contrast, another study found that thiopurines were associated with an increased risk of intra-abdominal septic complications (16\% vs $6 \%$ without therapy) (96).

Existing data do not suggest a significantly increased risk of perioperative infections or impaired wound healing with methotrexate. Given the lack of data, it may be reasonable to discontinue methotrexate at least 1 week before surgery in patients with a history of previous or severe septic complications, and resume if necessary no sooner than 1 week after surgery or when the wound has healed (97).

\section{Biologics}

There are conflicting results whether preoperative use of biologics increases risk of infectious complications (84). There are only limited data in children (98). A meta-analysis of the preoperative use of anti-TNF therapy in adults showed an increased prevalence of postoperative complications $(\mathrm{OR}=1.45,95 \%$ CI 1.04-2.02; 13 studies, 2538 patients), as well as for both infectious ( $\mathrm{OR}=1.47$, 95\% CI 1.08-1.99; 10 studies, 2116 patients) and noninfectious complications $(\mathrm{OR}=2.29,95 \%$ CI $1.14-4.61 ; 3$ studies, 729 patients) (99). All included studies are retrospective, patient groups are heterogeneous, the inclusion criteria and definitions of complications vary, and confounding effects of concomitant therapies are not defined. Patients treated with IFX were more likely to be treated with immunomodulators and steroids. Also, the patients usually had additional risk factors including adverse surgical outcomes, malnutrition, and urgent indications for an operation.

\section{Preoperative Nutrition}

\section{Practice point:}

Consider initiation of EEN (continuous or bolus if tolerated) for at least 2 weeks before imaging studies and surgery are performed. Attenuation of inflammation will improve distinction between bowel narrowing due to stricturing or inflammatory processes (100). This will allow the surgeon to plan the best approach (stricturoplasty or resection and minimize bowel loss). EEN will also allow reduction of corticosteroids, if given, and improvement of nutritional status.

Enteral support whenever possible is preferable to TPN to improve nutritional status because it is physiologic, is less costly, and has less potential for sepsis. A number of studies reported that poor nutritional status at the time of operation significantly increased the risk of postoperative complications and intra-abdominal infections in CD (101-104). Intra-abdominal septic complications were associated with hypoalbuminemia $<3.0 \mathrm{~g} / \mathrm{dL}(101)$ and the complication rate was $29 \%$ among 124 patients with low serum albumin levels $(<3.1 \mathrm{~g} / \mathrm{dL})$ but only $6 \%$ among patients with normal albumin levels (104). Improvement of nutritional status by TPN may contribute to a reduction of postoperative complications in both adult and pediatric patients $(103,105,106)$. Anastomotic dehiscence is consistently associated with a serum albumin levels $<3.5 \mathrm{~g} / \mathrm{dL}$ in elective colorectal resections in adults (for review (84)). In a study of 78 patients with penetrating $\mathrm{CD}$, preoperative management, including nutritional support and weaning off steroids, allowed ileocecal resection with low rates of postoperative morbidity (107).

\section{LONG-TERM POSTOPERATIVE COMPLICATIONS}

\footnotetext{
Statement 13. Vitamin B12 levels (active vitamin B12) should be routinely monitored in patients who undergo resection of $>\mathbf{2 0} \mathrm{cm}$ of terminal ileum. (Agreement $100 \%$ ) Statement 14. Bile acid malabsorption should be suspected in patients with persistent diarrhea despite clinical remission or limited disease activity after ileal resection. (Agreement 100\%)

Statement 15. The patient should be informed that after surgical resection, the risk of bowel obstruction is increased (either secondary to recurrent disease or adhesions). (Agreement 100\%)
} 
Practice points:

1. The risk of postsurgical functional impairment, although small, should be discussed before patients undergo intestinal resection. Bowel function is not often affected by localized small bowel or ileocecal resection. Subtotal colectomy and ileoanal anastomosis result in an increased frequency of defecation, but the functional outcome is good when CD stays in remission.

2. Ileal resection $<20 \mathrm{~cm}$ of bowel length is infrequently associated with vitamin B12 deficiency or bile acid malabsorption. Surgical treatment should aim to preserve bowel length by using bowel sparing techniques.

3. Methylmalonic acid may help in detecting early vitamin B12 deficiency (by itself or with a homocysteine test).

4. As stated in the "Selection of the type of surgery" section, ileal pouch-anal anastomosis should be avoided in CD. Repeated episodes of pouchitis are common and pouch failure may occur in $\mathrm{CD}$ patients with a pouch.

5. There is limited evidence that fertility may be lower in patients with $C D$ and this may be further enhanced by surgery $(108,109)$.

\section{Bowel Function}

There are limited data on postsurgical bowel function. Only 1 study with a small number of patients addressed the development of functional problems after small intestinal resection. Almost all children with limited ileal resection were continent, as were children with partial colectomy but this was based on only 6 children (37). Meta-analysis that compared segmental versus subtotal/total colectomy in adults found that more patients were continent after segmental colectomy (110). There are no pediatric data regarding bowel function after ileo-rectal anastomosis.

The only large study reporting functional outcomes after proctocolectomy and ileal pouch anal anastomosis (IPAA) in the pediatric population included 433 patients $(5.1 \%$ with UC patients postoperatively classified as CD) (111). Wound infection and pouch failure rates were significantly higher in patients with CD. Piekkala et al (37) reported a small pediatric study in which all patients with IPAA had experienced pouchitis and eventually, 4 of 8 patients needed bowel diversion. The latter study is the only study addressing the development of functional problems after small bowel resection but the study is retrospective with small number of patients. In adult patients functional results after IPAA are inconsistent and meta-analysis found no significant functional differences between CD and UC patients except for increased urgency and incontinence in CD patients (112-116). Other studies in adults reported that patients with proven $\mathrm{CD}$ who underwent IPAA developed $\mathrm{CD}$ of the pouch in $40 \%$ to $63 \%$ of cases during the 5 -year postoperative period $(117,118)$.

\section{Vitamin B12 Malabsorption}

Resection of the terminal ileum may lead to malabsorption of vitamin B12. Ahmed and Jenkins (119) reported the effect of small bowel surgery on vitamin B12 levels in 18 children with variable ileal resection due to $\mathrm{CD}$ for a period of 10 years. None of the children had low vitamin B12 levels before or after small bowel surgery suggesting that serum levels are poor indicators for actual needs. Recently, measurement of active vitamin B12 (transcobalamin-bound) has been adopted (120). A recently published systematic review in adults with IBD found that ileal resections greater than $30 \mathrm{~cm}$ were associated with vitamin B12 deficiency, whereas those patients with $<20 \mathrm{~cm}$ of resected ileum had normal serum vitamin B12 (121).

\section{Bile Acid Malabsorption}

Approximately $95 \%$ of bile acids are re-absorbed in the distal ileum and although their malabsorption can cause diarrhea, it is unusual to have steatorrhea with malabsorption of fat-soluble vitamins resulting in the formation of gallstones and kidney stones $(122,123)$. One pediatric study found that $23 \%$ of patients with CD had bile acid malabsorption (124). Patients with previous ileal resections (resected bowel length was $10-30 \mathrm{~cm}$ ) had significantly higher serum $\mathrm{C} 4$-concentrations ( $7 \alpha$-hydroxy-4-cholesten-3-one), suggesting bile acid malabsorption, than patients with ileal inflammation only (124). Adult studies showed bile acid malabsorption in $55 \%$ to $90 \%$ of patients who had terminal ileal resections (125-127).

Resection of the terminal ileum may lead to diarrhea due to bile acid malabsorption. When suspected, bile acid malabsorption may be confirmed indirectly by a short-term empirical treatment with bile acid-binding drugs, such as cholestyramine or colestipol. Measurement of serum $7 \alpha$-hydroxy-4-cholesten-3-one levels in serum may be helpful to establish a diagnosis when available (128). Measurement of whole body retention of a radioactive bile acid, SeHCAT (selenium-75-homocholic acid taurine) is not standardized.

\section{Quality of Life After Crohn Disease Surgery}

The quality of life (QoL) is in general good after CD surgery at pediatric age. Piekkala et al (37) found comparable QoL between the patients and controls, but when patients had school or work absences the QoL decreased. The type of surgery or the number of complications did not appear to have an effect on QoL. Two studies from the same center, performed on limited number of patients ( $\mathrm{n}=5$ in both studies) reported that stoma formation was associated with restricted sport activities in children $(129,130)$. On the other hand, Piekkala found no effect of permanent stoma on QoL in children compared to adult patients with a stoma who scored lower for general health and physical activity compared to controls $(37,131)$.

\section{Intestinal Obstruction}

One of the late complications of surgery in $\mathrm{CD}$ patients is intestinal obstruction. Pediatric data showed that the incidence of bowel obstruction caused by adhesions or anastomotic stricture varied from $1.2 \%$ to $9.1 \%$ for the first 12 to 24 months after the surgery $(29,31,53,132)$. Only 1 study reported bowel obstruction due to adhesions in $12 / 36(33.3 \%)$ and anastomotic stenosis/ stricture in $9 / 36(25 \%)$ of patients with a median follow-up of 10 years (37).

Strong evidence does not exist linking specific surgically related factors to the postoperative development of intestinal obstruction. A pediatric study found a higher risk to re-stricture following strictureplasty compared with resection (133); however, data are not uniform (50). Another proposed risk factor is end-toend anastomosis, but a meta-analysis of adult data found that endto-end anastomosis is not associated with an increased risk for obstruction $(134,135)$. One RCT in adults found that open surgery is more likely to cause obstruction compared with laparoscopic procedure, whereas another found no advantages of laparoscopic procedure over open surgery $(136,137)$. 


\section{Short Bowel Syndrome/Intestinal Failure}

Studies in adults found that the cumulative incidence for intestinal failure in CD is $1 \%$ after 5 years and $4.5 \%$ to $6.1 \%$ after 15 years from initial surgery $(138,139)$. Identified risk factors include penetrating disease type, remaining small intestine of $<200 \mathrm{~cm}$, ostomy creation and colectomy (140). Based on these observations, surgical treatment should preserve bowel length as much as possible by using bowel sparing techniques, including strictureplasty and limiting removal of the bowel to those areas associated with the symptoms $(141,142)$.

\section{Fertility}

Abdominal surgery in patients with severe inflammation may be associated with impaired fertility, whereas in less ill patients fertility is preserved as recently shown in a large cohort of women undergoing surgery for appendicitis (143). There are no studies on pediatric CD.

\section{SCHEDULE FOR FOLLOW-UP AFTER SURGERY}

\begin{abstract}
Statement 16. Postoperative medical treatment should be based on ileocolonoscopy assessment and not solely on symptoms or serum inflammatory markers. Repeated fecal biomarkers testing may aid in deciding on the timing of endoscopy. (Agreement 100\%)
\end{abstract}

Practice points:

1. Postoperative endoscopic evaluation should be performed at 6 to 9 months after surgery $(144,145)$.

2. Local recurrence limited to the anastomotic site (Rutgeerts i1), however, is common but does not indicate need for changing therapy in asymptomatic patients.

3. Fecal calprotectin is superior to C-reactive protein (CRP) and clinical disease activity indices in monitoring disease recurrence. It is advisable to test calprotectin level repeatedly during the follow-up to detect early asymptomatic recurrence. The scheme for most effective follow-up is not established but testing at least 2 to 3 times per year is advisable.

4. Magnetic resonance enterography, abdominal ultrasound, and wireless capsule endoscopy can detect disease recurrence but are not a substitute for endoscopy.

\section{Predictors of Early Recurrence}

There are no pediatric studies identifying predictors of early recurrence after surgical resection in $\mathrm{CD}$ but the risk is high $(27,35,37,38)$. In adults, there are recognized as risk factors for recurrence, such as smoking, penetrating disease, perianal disease, presence of granuloma in the resected segments, submucosal plexitis, or presence of extraintestinal manifestations (146).

Although clinical recurrence occurs in $30 \%$ during the first year after resection, approximately $80 \%$ show endoscopic recurrence that precedes clinical symptoms (147). Therefore, endoscopic recurrence is the strongest predictor of disease progression (148-151). Rutgeerts index is the most widely used measure to assess endoscopic lesions and has a strong predictive validity in adults (Table 2) $(151,152)$. Rutgeerts score $\geq i 2$ has higher risk of clinical recurrence at 4 years compared with score $<\mathrm{i} 2(100 \%$ vs $9 \%$, respectively) (151).

Monitoring to detect recurrence is important. Because publications dealing with this issue are almost all based on adult patients, pediatric recommendations have to be extrapolated. The

\begin{tabular}{ll}
\hline TABLE 2. Endoscopic recurrence after surgery \\
\hline Endoscopic score & \multicolumn{1}{c}{ Definition } \\
\hline i0 & No lesions \\
i1 & $\leq 5$ aphtous lesions \\
i2 & 5 aphtous lesions with normal mucosa between \\
& the lesions, or skip areas of larger lesions, or \\
& lesions confined to the ileocolic anastomosis \\
i3 & Diffuse aphtous ileitis with diffusely inflamed \\
& mucosa \\
i4 & Diffuse inflammation with already larger ulcers, \\
& nodules, and/or narrowing \\
\hline
\end{tabular}

Rutgeerts score (151).

recently published Australian randomized postoperative Crohn endoscopic recurrence trial (POCER) study evaluated the efficacy of endoscopically tailored treatment (153). A cohort of 174 adult CD patients was included and all received medical prophylaxis starting immediately after surgery. After randomization (2:1) further step-up in treatment was based upon findings at ileocolonoscopy at 6 months (endoscopy group) or clinical symptoms (control group). Ileocolonoscopy performed 18 months after surgery showed recurrence in $49 \%$ in the endoscopy group versus $67 \%(P=0.03)$ in the control group. Therefore, ileocolonoscopy performed 6 months after resection is recommended to monitor for postoperative recurrence (154). There is poor correlation between postoperative endoscopic recurrence and clinical symptoms, Crohn's disease activity index (CDAI) or blood inflammatory markers such as CRP $(12,27,147,155)$.

Fecal calprotectin may be used to screen patients who require colonoscopy for detecting mucosal recurrence and may be helpful in the timing of endoscopy $(156,157)$. This is supported by data from the POCER study, which shows that the level of calprotectin correlates well with endoscopic recurrence but not with CRP or CDAI $(153,158,159)$. Level of calprotectin $>100 \mu \mathrm{g} / \mathrm{g}$ indicated endoscopic recurrence with a sensitivity 0.89 and negative predictive value 0.91 . This means that colonoscopy could have been avoided in $47 \%$ of patients. Another adult study reported accordingly that the best cutoff point for calprotectin was $100 \mu \mathrm{g} / \mathrm{g}$ to distinguish between endoscopic remission and recurrence, with a sensitivity 0.95 and negative predictive value 0.93 (160). Such levels are, however, close to normal values, and therefore the level of calprotectin that practically should lead to endoscopy remains to be determined. There are no pediatric data yet on the strategy of follow-up after surgery. A small pediatric study reported that when compared with first postoperative fecal calprotectin, the concentration of calprotectin increased significantly more in patients with either endoscopic or histological recurrence versus no recurrence. The best cutoffs in pediatric patients were as follows: calprotectin $>139 \mu \mathrm{g} / \mathrm{g}$ or increase of $79 \mu \mathrm{g} / \mathrm{g}$ compared with first postoperative value were suggestive of endoscopic recurrence (Rutgeerts score i2-i4), while calprotectin $>101 \mu \mathrm{g} / \mathrm{g}$ or increase of $21 \mu \mathrm{g} / \mathrm{g}$ indicated histological recurrence (161). It must be, however, noted that exact levels of calprotectin may differ with specific brands; therefore, reference values must be determined locally according to the method used.

Abdominal US and CT can also be used for detection of disease recurrence, but because of radiation CT should be avoided in children, if possible (162). One study found magnetic resonance enterography to have a similar value in predicting postoperative recurrence as ileocolonoscopy (163). A number of small studies with conflicting data show that wireless capsule endoscopy may be used in detecting mucosal lesions post-surgery in selected patients (156-158). Presently none of these studies have, however, proven to be superior to ileocolonoscopy for disease sited within the reach 
of ileocolonoscopy. In patients with lesions of the small bowel then magnetic resonance enterography is more appropriate.

\section{PREVENTION OF RECURRENCE}

The risk of recurrence depends on several factors. Patients with extensive disease, short disease duration from diagnosis to surgery, recurrent surgery, long resected segment, surgery for fistulizing disease, disease complications, impaired growth, pubertal delay, perianal disease, or smoking habits may be categorized as having high risk and therefore need a more active follow-up.

\section{Thiopurines}

Statement 17. 1. Thiopurines may be used for preventing postoperative recurrence when a child has a moderate risk of CD recurrence. (Agreement 100\%)

Statement 18. 2. When thiopurines have failed preoperatively their postoperative use requires careful risk-benefit analysis. (Agreement 100\%)

\section{Practice point:}

1. Thiopurines should be considered after surgery in thiopurinenaïve patients with extensive disease or risk factors of relapse. When preoperatively adequately treated with thiopurines and disease activity results in surgery, the efficacy of using thiopurines in preventing recurrence is uncertain as most of the reported data of the postoperative efficacy come from patients previously treatement naïve. In patients pretreated with thiopurines, relapse prevention with methotrexate may be an option, but there are no specific data available.

Thiopurines (azathioprine [AZA] and 6-mercaptopurine [6MP]) have a well-established role in maintaining remission in $\mathrm{CD}$. Their efficacy in preventing postoperative recurrence is debated and all data come from adult studies (164-166). The ECCO 2010 guideline advocates their use postoperatively in patients with "highrisk" factors (13). Thiopurines were superior over 5-ASA in preventing any endoscopic recurrence at 12 months but not severe recurrence, and not clinical recurrence at 12 or 24 months (167170). Combining the only studies with a placebo arm, however, demonstrated that the use of thiopurine reduced clinical and severe endoscopic recurrence at 12 months $(169,171)$. The superiority of thiopurine over 5-ASA was shown in a third meta-analysis, although thiopurines were associated with more adverse events $(172,173)$. In the RCTs, most patients randomized to receive AZA/6-MP were thiopurine-naïve (previous thiopurine exposure in $7 \%$ in the D'Haens' study, $8.5 \%$ in the Ardizzone study, not specified in the Hanauer study) $(169,171,174)$. There is no evidence-based data on the use of MTX in preventing postoperative recurrence in pediatric CD.

\section{Biologics}

Statement 19. 1. Treatment with anti-TNF $\alpha$ is recommended when a CD patient has a high risk of postoperative recurrence or has widespread disease. (Agreement 100\%) Statement 20. 2. When a patient experiences endoscopic recurrence after intestinal resection despite optimal thiopurine treatment, the therapy should be escalated to antiTNF $\alpha$ medication. (Agreement 100\%)
Practice points:

1. Anti-TNF $\alpha$ treatment may be used postoperatively if the patient has been a primary responder, did not develop anti-TNF antibodies and also in those with widespread disease, that is, active disease beyond the resected site.

2. Those with reintroduction of anti-TNF $\alpha$ after an interval of $>12$ weeks need careful monitoring for development of antibody-associated loss of response.

3. Early endoscopic evaluation after surgery (suggested 6 months) has been shown to be adequate to help decide when to introduce anti-TNF $\alpha$ in patients without apparent disease after surgery (153).

Evidence for prophylactic anti-TNF $\alpha$ use in postoperative recurrence is based on several small clinical trials in adults summarized in Supplemental Digital Content, Table 1, http://links.lww.com/MPG/A936. The most recent RCT study, POCER study, concluded that selective immune suppression, adjusted for early recurrence, rather than routine use, leads to disease control in most patients (153).

Most of the adult studies cited did not include patients previously treated with anti-TNF $\alpha$. In the randomized, doubleblinded, placebo-controlled study on anti-TNF $\alpha$ in postoperative $\mathrm{CD}$, there were only 8 patients who had received prior IFX $(30 \%$ in the IFX group) within 6 months of surgery (number of infusions 14) (155). Patients with fibrostenosis or penetrating disease were not considered true primary nonresponders, but rather had developed complications that required surgery. In the POCER study no more than one-third of the studied patients had previously received antiTNF $\alpha(21 \%$ and $29 \%$ of the active care and the standard care groups, respectively) (153). Therefore, there is insufficient data to establish if anti-TNF $\alpha$ agents are less effective in preventing recurrence if prescribed for the patient who failed treatment before the surgery as compared to the anti-TNF $\alpha$-naïve patient. Also, the presence of drug antibodies underlying loss of response is less reported. The use of IFX reduced the rate of endoscopic but not clinical recurrence (175).

One study reported benefit from lower doses of anti-TNF $\alpha$ (IFX $3 \mathrm{mg} / \mathrm{kg}$ ) to maintain remission but trough levels were not measured (176). Thus, this approach is not recommended in pediatric patients.

\section{Other Medications}

\section{Practice point:}

1. The evidence is weak to support the use of the following postoperative prevention medications: 5-ASA/sulfasalazine, budesonide, antibiotics, and probiotics.

There are no pediatric studies evaluating these medications. Trials of mesalazine therapy ( $3-4 \mathrm{~g} /$ day) showed a significant reduction of risk of clinical (relative risk [RR] $0.76,95 \% \mathrm{CI}$ $0.62-0.94$ ) and severe endoscopic recurrence (RR $0.50,95 \% \mathrm{CI}$ $0.38-0.92)$ in adults but the number needed to treat for these outcomes was high (12 and 7, respectively) (169,177-181). Also, nitroimidazole antibiotics (eg, metronidazole) have been used to prevent relapse, but they may not produce added benefit when used as concomitant therapy with AZA (182). Adverse effects may limit long-term use in children. A Cochrane review, which evaluated 2 adult trials, concluded that the risk of clinical and endoscopic recurrence was reduced with nitroimidazole antibiotics compared with placebo (RR $0.23,95 \% 0.09-0.57$, number needed to treat $=4$ and RR $0.44,95 \%$ CI $0.26-0.74$, number needed to treat $=4$ ) 
$(164,183,184)$. In 1 trial metronidazole was administered for 3 months and in the other, ornidazole for 1 year. Results for ciprofloxacin $(500 \mathrm{mg}$ bid for 6 months vs placebo) have been disappointing in a recent pilot RCT (185). Budesonide and probiotics are ineffective in relapse prevention (186-191).

Partial EN may be an effective treatment option to prevent postoperative recurrence based on a nonrandomized prospective study in 40 adult CD patients with ileal or ileocolonic resection (192). In the EN group, 1 of 20 patients developed clinical recurrence compared with 7 of 20 in the non-EN group during 1-year follow-up (endoscopic recurrence rates were 30\% vs 70\%, respectively). EN consisted of nocturnal infusion of elemental diet (via nasogastric tube) along a low-fat diet during the day for 12 months, compared with no nutritional intervention (non-EN group). All of the patients received 5-ASA medication. The treatment acceptability was low $(50 \%)$. The beneficial effect of $\mathrm{EN}$ in preventing postoperative recurrence following resection was further supported by a 5-year follow-up study (193). Another nonrandomized study from Japan suggested a benefit in preventing postoperative recurrence from taking $>50 \%$ of calories in the form of EN (194). No pediatric trial to date has evaluated the potential or efficacy of postoperative EN in preventing recurrence.

\section{HOW TO CHOOSE THE TYPE OF POSTOPERATIVE MAINTENANCE MEDICATION}

Selecting the most appropriate therapeutic intervention for prevention of postoperative recurrence of $\mathrm{CD}$ remains a challenging clinical problem, especially in children in whom there is a lack of Level 1 evidence. Although the majority of patients with CD will eventually require surgery, most of those who are left untreated postoperatively will develop disease recurrence within a few years and many will need reoperation within 10 years $(37,38,195)$. Given the fact that children who undergo resection have a lifelong risk for repeated resections and are at risk to develop short bowel syndrome, the issue of preventing recurrence is of the greatest importance. The suggested algorithm is presented in Figure 1.

Practice points:

1. Low-risk patients may be given no prophylaxis medication after surgery or only 5-ASA if signs of colonic involvement. Maintenance enteral nutrition may also be considered $(196,197)$.

2. In high-risk patients (extensive disease, short disease duration from diagnosis to surgery, recurrent surgery, long resected segment, surgery for fistulizing disease, disease complications, perianal disease, smoking) anti-TNF $\alpha$ is the most effective therapy, even in patients who were treated before surgery.

3. Ileocolonoscopy is recommended 6 to 9 months after surgery with treatment step-up if Rutgeerts score is $\geq \mathrm{i} 2$ )

4. Fecal calprotectin may be evaluated at regular intervals, for example, every 3 to 6 months, with further endoscopy in case of significant increase. Most published studies suggest best cutoff level of fecal calprotectin as $100 \mu \mathrm{g} / \mathrm{g}$ for predicting endoscopic recurrence but lower values of 60 or $75 \mu \mathrm{g} / \mathrm{g}$ have also been suggested $(198,199)$.

The role of endoscopy-guided treatment to modify clinical outcome has been evaluated in several adult retrospective studies with conflicting results $(158,200,201)$. A prospective study $(174$ patients enrolled) revealed that at 18 months after surgery recurrence occurred in $49 \%$ versus $67 \%$ (randomization $2: 1$ to either endoscopy tailored treatment at 6 months postoperatively or control group $(P=0.028)$; patients in both groups received prophylaxis starting immediately after surgery (153). A small Japanese prospective study with a 5-year follow-up period has revealed comparable results (193). Alike in adults, a constant rise in fecal calprotectin is suggestive of disease recurrence in children (161).

\section{PERIANAL DISEASE}

Perianal CD is a complex condition that is frequently refractory to treatment and needs a combined medical and surgical approach. In adult CD, up to $54 \%$ of patients present with perianal complications, perianal fistulas develop in $20 \%$ and recurrence occurs in approximately $30 \%$ of patients $(202,203)$. The majority of patients with perianal fistulas have colonic disease involving the rectum (204). Perianal manifestations including fissures and skin tags are present in $13 \%$ to $62 \%$ of children with CD (205). Perianal fistulas are present in $10 \%$ to $15 \%$ of the time at diagnosis (206-208).

\section{Diagnostic Approach}

Various fistula classifications have been proposed either relating fistulas to the ano-rectal ring (high or low) or more precisely as described by Parks, using the external sphincter as the reference point (29). For clinical practice, classification into simple (superficial involvement of the external sphincter by single fistula tract without rectal inflammation or abscess) and complex (deep or extensive involvement of the sphincter musculature by fistula tract or associated rectal inflammation, abscess or stenosis) perianal fistula is more relevant $(207,210,211)$. For the management of perianal fistulizing $\mathrm{CD}$ it is essential locate the fistula origin, establish the anatomical course of the fistula tract and exclude or identify the presence of associated rectal inflammation or abscess $(207,211,212)$.

\section{Statement 21. Pelvic MRI and evaluation under anesthesia by a surgeon with experience in pediatric anorectal dis- ease should be among the initial procedures in evaluating a child with suspected complex perianal CD. (Agreement $100 \%$ ) \\ Statement 22. Disease extension should be re-evaluated by ileocolonscopy in all patients with complex perinanal disease manifesting after primary diagnostic investi- gations of CD. Concomitant intestinal lesions (inflam- mation, stenosis) have both prognostic and therapeutic relevance. (Agreement 100\%)}

When the child has perianal pain an abscess is almost always present. In such situations prompt evaluation under anesthesia, including drainage, is the procedure of choice to minimize damage to the sphincter (212-214). Nevertheless, pelvic MRI has an accuracy of $76 \%$ to $100 \%$ for fistulae in studies performed in adults and it has become an essential tool as well for children providing important information for the surgeon about the tract of the fistula and identifying an abscess (203,214-219). When pain is not present, most children will tolerate a gentle digital rectal examination to identify a stricture or fluctuance. The most common approach to evaluate perianal CD for children involves an external and rectal examination followed by MRI imaging and examination under anesthesia by an experienced surgeon (212). Fistulography is rarely needed for evaluation of the fistula tract. Endoscopic ultrasound has also been used to diagnose and guide management of perianal disease with satisfactory result (220). Disease extension should be re-evaluated by ileocolonoscopy in all patients with complex perianal disease that develops after primary diagnostic investigations of $\mathrm{CD}$. 


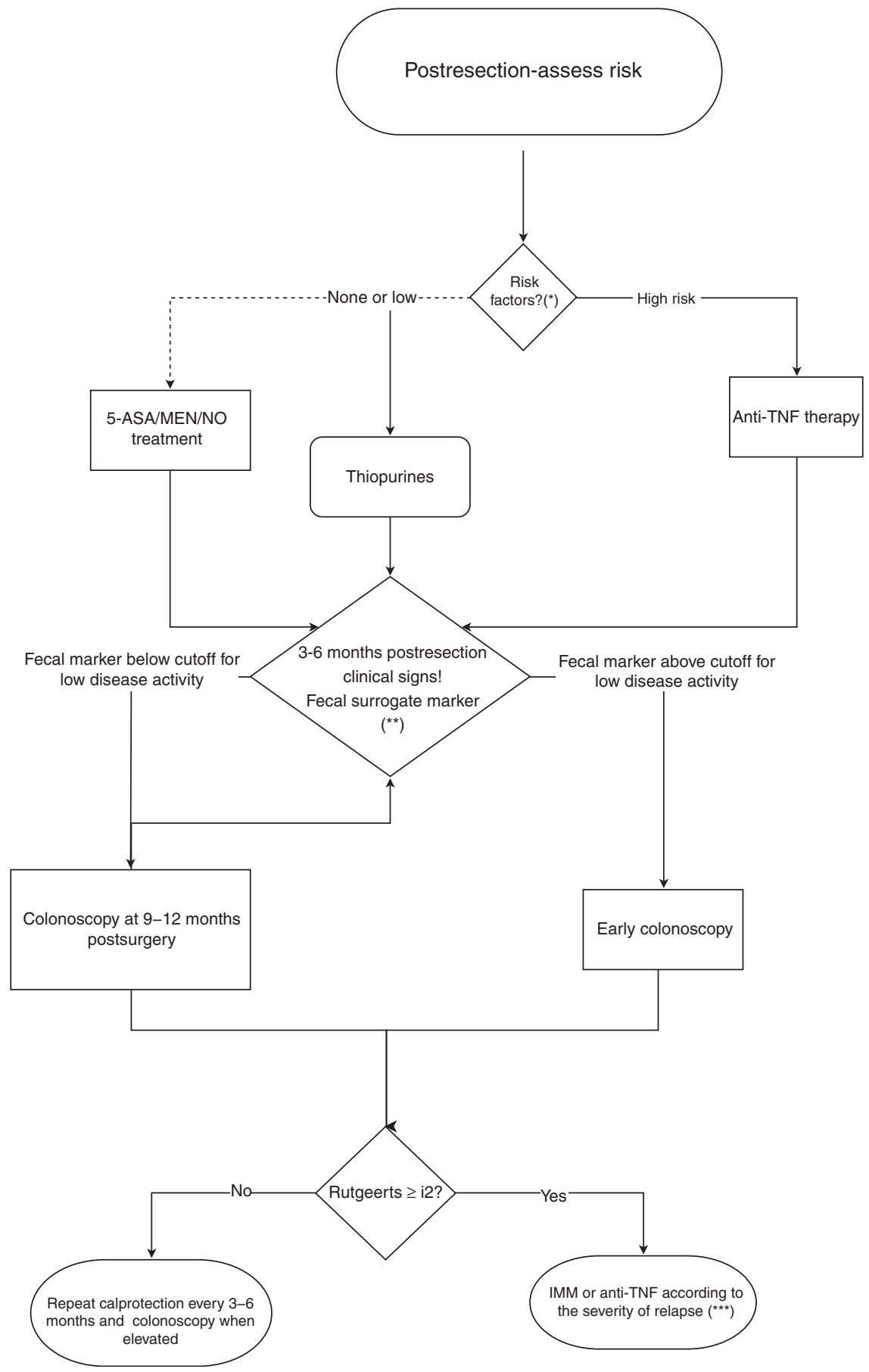

FIGURE 1. Therapeutic algorithm for preventing postoperative recurrence in pediatric Crohn disease. $\left(^{*}\right)$ High-risk factors are growth failure, delayed puberty, short duration from diagnosis to surgery, extensive resection $(>40 \mathrm{~cm})$, penetrating behavior, active disease beyond resected site. $\left({ }^{* *}\right)$ Fecal markers cutoff according to local reference value (see text, Section 10 , practice point 4 ). $\left({ }^{* * *}\right)$ Decision of the given therapy according to the severity of relapse and disease history. IMM=immunomodulator; $\mathrm{MEN}=$ maintenance enteral nutrition.

A less common condition described as severely destructive form, separate to the more commonly recognized perianal disease is reported rarely but is a real treatment challenge. Markowitz et al (221) were the first to report in 1995 such a severe and mutilating form and named it highly destructive perianal disease (HDPD). They identified 67 of 230 patients (29\%) (children and adolescents) with perianal disease of which only 6 (2.6\% of total children) were described with HDPD. Since then there have been a few other case reports highlighting the severity of the condition and difficulty of treatment (222-225). It is characterized by visualization of deep perianal ulceration and tissue destruction associated with copious exudate with involvement of perineum and surrounding areas. 
Unfortunately, HDPD is not particularly responsive to medical therapies including hyperbaric oxygen even with the advent of biologics and often diverting the fecal stream via an ostomy to promote perianal healing is the only effective form of management. Successful skin grafting of the perianal ulceration following fecal stream diversion has been described $(223,225)$.

\section{Treatment of Perianal Fistulae}

Statement 23. Treatment of perianal CD should be based on combination of surgery, antibiotics and biologics. (Agreement 100\%)

Statement 24. Presence of perianal abscess should be ruled out early and when detected drainage should be discussed with the surgeon. (Agreement 100\%)

Statement 25. Placement of noncutting seton should be considered in all complex fistula tracts, especially in those with recurrent abscesses. (Agreement 100\%)

Practice points:

1. In asymptomatic simple perianal fistulae no actions are needed but careful monitoring is recommended.

2. Symptomatic simple fistulae should be treated either with placement of noncutting seton or in superficial cases with fistulotomy.

3. Uncomplicated fissures may be treated with topical therapy.

4. Anti-TNF $\alpha$ agents should be used as primary medical induction therapy for complex perianal $\mathrm{CD}$ in combination with appropriate surgical intervention after effective abscess drainage. After successful induction, anti-TNF $\alpha$ scheduled maintenance is mandatory. Antibiotics may be used as second line medical treatment until drainage from the abscess or fistula has stopped. The evidence for the use of AZA-6MP is weak.

5. Antibiotics, metronidazole $\left(20-30 \mathrm{mg} \cdot \mathrm{kg}^{-1} \cdot \mathrm{day}^{-1}\right)$ or ciprofloxacin $\left(10-20 \mathrm{mg} \cdot \mathrm{kg}^{-1} \cdot \mathrm{day}^{-1}\right)$ are most widely used.

6. The timing of removal of setons depends on subsequent therapy and treatment response.

7. Anti-TNF $\alpha$ should be continued for at least 1 year following with abscess drainage.

8. In case of failure of IFX, ADA is recommended. In case of failure to respond to available anti-TNF $\alpha$ agents and other biologics with proven efficacy in CD, AZA/6-MP, methotrexate, or tacrolimus with antibiotics may be used.

9. The use of cutting setons may damage anal sphincter and induce incontinence.

10. Fistulectomy and fistulotomy carry a risk of incontinence and therefore should only be performed by expert surgeons (13). Endorectal mucosal advanced flap is an option in the absence of rectal disease and in case of a single fistula source that it is easily identified.

11. Proctectomy (and permanent diversion) may be considered when a patient has severe rectal and perianal disease.

When a simple perianal fistula is symptomatic there is consensus in adults to use antibiotics as the first therapeutic option, azathioprine/6-mercaptopurine (AZA/6-MP) as the second option and IFX as a third option. Combined medical and surgical approach is favored (212).

There is lack of controlled evidence on the efficacy of antibiotics that are the first-line therapy especially in simple fistula in children and adults $(209,211,212)$. There are no controlled trials assessing the effect of AZA/6-MP on the closure of perianal fistulae as primary endpoint $(204,226,227)$. Small uncontrolled series on efficacy of intravenous cyclosporine A and oral tacrolimus have been reported $(228,229)$.

In adults, IFX was the first agent shown to be effective in an RCT for inducing closure of perianal fistulae and maintaining response over 1 year (complete closure in $55 \%$ vs $13 \%$ in the placebo group) (230). In another trial, randomized controlled trial to assess the efficacy and safety of repeated infusions of infliximab in patients who improved after an initial infusion of infliximab (ACCENT) II, complete closure was seen in 36\% at week 54 . Comparable results with ADA (Crohn trial of the fully human antibody adalimumab for remission maintenance [CHARM]) have been observed in adults $(231,232)$. Results on the use of ADA following IFX failure or intolerance are conflicting $(233,234)$. In fistulizing disease, maintenance on IFX reduced hospitalization and surgery $(235,236)$.

In pediatrics the post-hoc analysis of 22 patients with perianal CD of REACH study, response rates were $41 \%$ at week 2 and $72 \%$ at week 54 (237). In another study, long-term clinical response to IFX was observed in 9 of 16 patients with refractory CD and draining fistulae (238). Top down strategy compared with a step up approach in a small group of pediatric patients showed better results (3/6 in the step up group compared with $12 / 12$ completely closed in the top down group) at 1 year (239). As of yet there are no published studies on the use of ADA in this context.

The combination of IFX and surgery with seton placement gives better results, longer effect duration and lower rate of recurrence to either treatment alone most likely related to better drainage of the abscess and fistulae (240-243). One strategy is to place seton before the start of therapy with IFX. Loose noncutting setons are used because a cutting seton may cause damage to the anal sphincter resulting in incontinence (207). In a recent retrospective study in 13 adolescent patients with complex perianal fistulae treated with seton placement and then IFX, >90\% responded. Fistula response 8 weeks was complete in $77 \%$ and partial in $15 \%$. Fistula recurred in $3 / 13(23 \%)$ patients, 2 on biological therapy and 1 after discontinuation of treatment (244). The loss of response to biological therapy was associated with detectable drug antibodies.

Anti-TNF $\alpha$ medication may be used as a first choice of treatment for complex perianal CD following radical surgery of "Cone-like" fistulectomy of each fistula tract with sparing of the sphincter (211). In the recent ECCO/ESPGHAN pediatric guidelines for medical management of CD anti-TNF $\alpha$ therapy is recommended as primary induction and maintenance therapy for children with active perianal fistulizing disease in combination with appropriate surgical intervention (11). The tract may persist as assessed by MRI and drainage usually recurs if treatment is stopped (212). Surgical treatment always is considered indicated for complex perianal CD. A perianal abscess should always be drained.

There is uncontrolled evidence that local injection of IFX close to the fistula tract may be beneficial in patients not responding to or intolerant of intravenous IFX $(11,245)$. Also, intralesional administration of mesenchymal stem cells has been reported as a promising treatment option in complex perianal fistula in adults (246).

A diverting ostomy or proctectomy may be necessary for severe disease refractory to medical therapy. In such patients the risk of the ostomy becoming permanent is significant (207). Rectal stenosis or strictures are relatively rare findings in children with CD and most commonly located at the dentate line. They may respond to repeated anal dilatation under anesthesia. A refractory short stricture may be amenable for stricturoplasty, whereas more extensive strictures may require fecal diversion with or without proctectomy. 


\section{Other Fistulizing Crohn Disease}

The most common fistulae in CD are enteroenteric. Surgical management typically involves resection of the diseased segment of bowel and closure of the connection with uninvolved intestine. Similarly, enterovesical fistula are managed by resection of the diseased segment and primary closure of the bladder.

\section{Enterocutaneous Fistulae}

Management of enterocutanoeus fistulae reported in children with CD is a complex challenge (36). IFX had modest effect on 25 patients out of 282 with rectovaginal fistulae (236). Early reoperation to close a fistula tract is often associated with recurrence or further complications. Optimizing the nutritional status is of importance in such situations (212).

\section{Enterogynecalogical Fistulae}

In low anal-introital asymptomatic fistula surgery may not be necessary. In patients with symptomatic fistula surgery may be necessary including diverting ostomy.

Rectovaginal fistulae have been rarely reported in children $(221,247)$. Surgery for such a condition should be tailored individually. Resection of the diseased gut segment is usually necessary when small bowel or sigmoid-gynecological fistulae are present (212). Rectovaginal fistulae not responding to conservative treatment should be treated surgically with an advancement flap and diverting-ostomy when necessary because of the presence of unacceptable symptoms $(212,248-251)$. In recurrent fistulizing disease gracilis muscle interposition has been successfully reported $(252,253)$.

\section{REFERENCES}

1. Walters TD, Griffiths AM. Mechanisms of growth impairment in pediatric Crohn's disease. Nat Rev Gastroenterol Hepatol 2009;6: $513-23$.

2. Chouraki V, Savoye G, Dauchet L, et al. The changing pattern of Crohn's disease incidence in northern France: a continuing increase in the 10- to 19-year-old age bracket (1988-2007). Aliment Pharmacol Ther 2011;33:1133-42.

3. Cosnes J, Gower-Rousseau C, Seksik P, et al. Epidemiology and natural history of inflammatory bowel diseases. Gastroenterology 2011;140:1785-94.

4. Gasparetto M, Guariso G. Highlights in IBD epidemiology and its natural history in the paediatric age. Gastroenterol Res Pract 2013; 2013:829040

5. Levine A, de Bie CI, Turner D, et al. Atypical disease phenotypes in pediatric ulcerative colitis: 5-year analyses of the EUROKIDS Registry. Inflamm Bowel Dis 2013;19:370-7.

6. de Bie CI, Paerregaard A, Kolacek S, et al. Disease phenotype at diagnosis in pediatric Crohn's disease: 5-year analyses of the EUROKIDS Registry. Inflamm Bowel Dis 2013;19:378-85.

7. Gupta N, Cohen SA, Bostrom AG, et al. Risk factors for initial surgery in pediatric patients with Crohn's disease. Gastroenterology 2006;130:1069-77.

8. Vernier-Massouille G, Balde M, Salleron J, et al. Natural history of pediatric Crohn's disease: a population-based cohort study. Gastroenterology 2008; 135:1106-13.

9. Pigneur B, Seksik P, Viola S, et al. Natural history of Crohn's disease: comparison between childhood- and adult-onset disease. Inflamm Bowel Dis 2010;16:953-61.

10. Bemelman WA, Allez M. The surgical intervention: Earlier or never? Best Pract Res Clin Gastroenterol 2014;28:497-503.

11. Ruemmele FM, Veres G, Kolho KL, et al. Consensus guidelines of ECCO/ESPGHAN on the medical management of pediatric Crohn's disease. J Crohns Colitis 2014;8:1179-207.
12. Caprilli R, Gassull MA, Escher JC, et al. European evidence based consensus on the diagnosis and management of Crohn's disease: special situations. Gut 2006;55(suppl 1):i36-58.

13. Van Assche G, Dignass A, Reinisch W, et al. The second European evidence-based consensus on the diagnosis and management of Crohn's disease: special situations. J Crohns Colitis 2010;4:63-101.

14. Homer DR, Grand RJ, Colodny AH. Growth, course, and prognosis after surgery for Crohn's disease in children and adolescents. Pediatrics 1977;59:717-25.

15. Sedgwick DM, Barton JR, Hamer-Hodges DW, et al. Population-based study of surgery in juvenile onset Crohn's disease. Br J Surg 1991; 78:171-5.

16. Hyams JS, Lerer T, Griffiths A, et al. Long-term outcome of maintenance infliximab therapy in children with Crohn's disease. Inflamm Bowel Dis 2009;15:816-22.

17. Wewer V, Riis L, Vind I, et al. Infliximab dependency in a national cohort of children with Crohn's disease. J Pediatr Gastroenterol Nutr 2006;42:40-5.

18. de Ridder L, Rings EH, Damen GM, et al. Infliximab dependency in pediatric Crohn's disease: long-term follow-up of an unselected cohort. Inflamm Bowel Dis 2008;14:353-8.

19. Crombe V, Salleron J, Savoye G, et al. Long-term outcome of treatment with infliximab in pediatric-onset Crohn's disease: a populationbased study. Inflamm Bowel Dis 2011;17:2144-52.

20. Hyams JS, Crandall W, Kugathasan S, et al. Induction and maintenance infliximab therapy for the treatment of moderate-to-severe Crohn's disease in children. Gastroenterology 2007;132:863-73.

21. Ruemmele FM, Lachaux A, Cezard JP, et al. Efficacy of infliximab in pediatric Crohn's disease: a randomized multicenter open-label trial comparing scheduled to on demand maintenance therapy. Inflamm Bowel Dis 2009;15:388-94.

22. Hyams JS, Griffiths A, Markowitz J, et al. Safety and efficacy of adalimumab for moderate to severe Crohn's disease in children. Gastroenterology 2012;143:365.e2-74.e2.

23. Chatu S, Subramanian V, Saxena S, et al. The role of thiopurines in reducing the need for surgical resection in Crohn's disease: a systematic review and meta-analysis. Am J Gastroenterol 2014;109: $23-34$.

24. Costa J, Magro F, Caldeira D, et al. Infliximab reduces hospitalizations and surgery interventions in patients with inflammatory bowel disease: a systematic review and meta-analysis. Inflamm Bowel Dis 2013;19: 2098-110.

25. Jakobsen C, Paerregaard A, Munkholm P, et al. Pediatric inflammatory bowel disease: increasing incidence, decreasing surgery rate, and compromised nutritional status: a prospective population-based cohort study 2007-2009. Inflamm Bowel Dis 2011;17:2541-50.

26. Afzal NA, Ozzard A, Keady S, et al. Infliximab delays but does not avoid the need for surgery in treatment-resistant pediatric Crohn' disease. Dig Dis Sci 2007;52:3329-33.

27. Buisson A, Chevaux JB, Allen PB, et al. Review article: the natural history of postoperative Crohn's disease recurrence. Aliment Pharmacol Ther 2012;35:625-33.

28. Abraham BP, Mehta S, El-Serag HB. Natural history of pediatric-onset inflammatory bowel disease: a systematic review. J Clin Gastroenterol 2012;46:581-9.

29. Diamond IR, Gerstle JT, Kim PC, et al. Outcomes after laparoscopic surgery in children with inflammatory bowel disease. Surg Endosc 2010;24:2796-802.

30. Pacilli M, Eaton S, Fell JM, et al. Surgery in children with Crohn disease refractory to medical therapy. J Pediatr Gastroenterol Nutr 2011;52:286-90.

31. Blackburn SC, Wiskin AE, Barnes C, et al. Surgery for children with Crohn's disease: indications, complications and outcome. Arch Dis Child 2014;99:420-6.

32. Benchimol EI, Guttmann A, To T, et al. Changes to surgical and hospitalization rates of pediatric inflammatory bowel disease in Ontario, Canada (1994-2007). Inflamm Bowel Dis 2011;17:2153-61.

33. Debruyn JC, Soon IS, Hubbard J, et al. Nationwide temporal trends in incidence of hospitalization and surgical intestinal resection in pediatric inflammatory bowel diseases in the United States from 1997 to 2009. Inflamm Bowel Dis 2013;19:2423-32. 
34. Van Limbergen J, Russell RK, Drummond HE, et al. Definition of phenotypic characteristics of childhood-onset inflammatory bowel disease. Gastroenterology 2008;135:1114-22.

35. Boualit M, Salleron J, Turck D, et al. Long-term outcome after first intestinal resection in pediatric-onset Crohn's disease: a populationbased study. Inflamm Bowel Dis 2013;19:7-14.

36. Gupta N, Bostrom AG, Kirschner BS, et al. Incidence of stricturing and penetrating complications of Crohn's disease diagnosed in pediatric patients. Inflamm Bowel Dis 2010;16:638-44.

37. Piekkala M, Pakarinen M, Ashorn M, et al. Long-term outcomes after surgery on pediatric patients with Crohn disease. J Pediatr Gastroenterol Nutr 2013;56:271-6.

38. Hansen LF, Jakobsen C, Paerregaard A, et al. Surgery and postoperative recurrence in children with crohn disease. J Pediatr Gastroenterol Nutr 2015;60:347-51.

39. Griffiths AM. Growth retardation in early-onset inflammatory bowel disease: should we monitor and treat these patients differently? Dig Dis 2009;27:404-11.

40. Werkstetter KJ, Pozza SB, Filipiak-Pittroff B, et al. Long-term development of bone geometry and muscle in pediatric inflammatory bowel disease. Am J Gastroenterol 2011;106:988-98.

41. Hyams JS. Inflammatory bowel disease. Pediatr Rev 2005;26:314-20.

42. Qasim A, Ullah N, Crotty P, et al. A changing trend in the management of patients with newly diagnosed Crohn's disease. Ir J Med Sci 2011;180:643-7.

43. Davies G, Evans CM, Shand WS, et al. Surgery for Crohn's disease in childhood: influence of site of disease and operative procedure on outcome. Br J Surg 1990;77:891-4.

44. Baldassano RN, Han PD, Jeshion WC, et al. Pediatric Crohn's disease: risk factors for postoperative recurrence. Am J Gastroenterol 2001;96:2169-76.

45. Griffiths AM, Wesson DE, Shandling B, et al. Factors influencing postoperative recurrence of Crohn's disease in childhood. Gut 1991;32:491-5.

46. Hojsak I, Kovačević D, Mišak Z, et al. The role of elective surgery in children with localized Crohn's disease. Paediatr Croat 2010;54:5.

47. Singh Ranger G, Lamparelli MJ, Aldridge A, et al. Surgery results in significant improvement in growth in children with Crohn's disease refractory to medical therapy. Pediatr Surg Int 2006;22:347-52.

48. Sentongo TA, Stettler N, Christian A, et al. Growth after intestinal resection for Crohn's disease in children, adolescents, and young adults. Inflamm Bowel Dis 2000;6:265-9.

49. Heuschkel RB, Menache CC, Megerian JT, et al. Enteral nutrition and corticosteroids in the treatment of acute Crohn's disease in children. J Pediatr Gastroenterol Nutr 2000;31:8-15.

50. Romeo E, Jasonni V, Caldaro T, et al. Strictureplasty and intestinal resection: different options in complicated pediatric-onset Crohn disease. J Pediatr Surg 2012;47:944-8.

51. Simon T, Orangio G, Ambroze W, et al. Laparoscopic-assisted bowel resection in pediatric/adolescent inflammatory bowel disease: laparoscopic bowel resection in children. Dis Colon Rectum 2003;46:132531.

52. Ba'ath ME, Mahmalat MW, Kapur P, et al. Surgical management of inflammatory bowel disease. Arch Dis Child 2007;92:312-6.

53. Bonnard A, Fouquet V, Berrebi D, et al. Crohn's disease in children. Preliminary experience with a laparoscopic approach. Eur J Pediatr Surg 2006;16:90-3.

54. Sica GS, Iaculli E, Benavoli D, et al. Laparoscopic versus open ileocolonic resection in Crohn's disease: short- and long-term results from a prospective longitudinal study. J Gastrointest Surg 2008;12:1094102 .

55. Laituri CA, Fraser JD, Garey CL, et al. Laparoscopic ileocecectomy in pediatric patients with Crohn's disease. J Laparoendosc Adv Surg Tech A 2011;21:193-5.

56. von Allmen D, Markowitz JE, York A, et al. Laparoscopic-assisted bowel resection offers advantages over open surgery for treatment of segmental Crohn's disease in children. J Pediatr Surg 2003;38:963-5.

57. Linden BC, Bairdain S, Shamberger RC, et al. Technique of laparoscopic-assisted total proctocolectomy and ileal pouch anal anastomosis in children and adolescents: a single center's 8-year experience. J Pediatr Surg 2012;47:2345-8.
58. Mamula P, Telega GW, Markowitz JE, et al. Inflammatory bowel disease in children 5 years of age and younger. Am J Gastroenterol 2002;97:2005-10.

59. Lindberg E, Lindquist B, Holmquist L, et al. Inflammatory bowel disease in children and adolescents in Sweden, 1984-1995. J Pediatr Gastroenterol Nutr 2000;30:259-64.

60. Polle SW, Slors JF, Weverling GJ, et al. Recurrence after segmental resection for colonic Crohn's disease. Br J Surg 2005;92:1143-9.

61. Bousvaros A, Sylvester F, Kugathasan S, et al. Challenges in pediatric inflammatory bowel disease. Inflamm Bowel Dis 2006;12: 885-913.

62. Smith NP, Ba'ath ME, Perry D, et al. BAPS UK inflammatory bowel disease surgical practice survey. J Pediatr Surg 2007;42:296-9.

63. Harper PH, Truelove SC, Lee EC, et al. Split ileostomy and ileocolostomy for Crohn's disease of the colon and ulcerative colitis: a 20 year survey. Gut 1983;24:106-13.

64. Peyrin-Biroulet L, Harmsen WS, Tremaine WJ, et al. Cumulative length of bowel resection in a population-based cohort of patients with Crohn's disease. Clin Gastroenterol Hepatol 2016;14:1439-44.

65. Martel P, Betton PO, Gallot D, et al. Crohn's colitis: experience with segmental resections; results in a series of 84 patients. J Am Coll Surg 2002;194:448-53.

66. Tersigni R, Alessandroni L, Barreca M, et al. Does stapled functional end-to-end anastomosis affect recurrence of Crohn's disease after ileocolonic resection? Hepatogastroenterology 2003;50:1422-5.

67. Bernell O, Lapidus A, Hellers G. Recurrence after colectomy in Crohn's colitis. Dis Colon Rectum 2001;44:647-54.

68. Yamamoto T, Keighley MR. Fate of the rectum and ileal recurrence rates after total colectomy for Crohn's disease. World J Surg 2000;24:125-9.

69. Kariv Y, Remzi FH, Strong SA, et al. Ileal pouch rectal anastomosis: a viable alternative to permanent ileostomy in Crohn's proctocolitis patients. J Am Coll Surg 2009;208:390-9.

70. Dignass A, van AG, Lindsay JO, et al. The second European evidencebased Consensus on the diagnosis and management of Crohn's disease: current management. J Crohns Colitis 2010;4:28-62.

71. Shen B. Crohn's disease of the ileal pouch: reality, diagnosis, and management. Inflamm Bowel Dis 2009;15:284-94.

72. Shen B, Remzi FH, Hammel JP, et al. Family history of Crohn's disease is associated with an increased risk for Crohn's disease of the pouch. Inflamm Bowel Dis 2009;15:163-70.

73. Fazio VW, Kiran RP, Remzi FH, et al. Ileal pouch anal anastomosis: analysis of outcome and quality of life in 3707 patients. Ann Surg 2013;257:679-85.

74. Patton D, Gupta N, Wojcicki JM, et al. Postoperative outcome of colectomy for pediatric patients with ulcerative colitis. J Pediatr Gastroenterol Nutr 2010;51:151-4.

75. Kelley-Quon LI, Tseng CH, Jen HC, et al. Postoperative complications and health care use in children undergoing surgery for ulcerative colitis. J Pediatr Surg 2012;47:2063-70.

76. McMullin CM, Morton J, Vickramarajah S, et al. A comparison of outcomes for adults and children undergoing resection for inflammatory bowel disease: is there a difference? ISRN Gastroenterol 2014;2014:410753.

77. Barrena S, Martinez L, Hernandez F, et al. Surgical treatment of chronic inflammatory bowel disease in children. Pediatr Surg Int 2011;27:385-90.

78. Frolkis A, Kaplan GG, Patel AB, et al. Postoperative complications and emergent readmission in children and adults with inflammatory bowel disease who undergo intestinal resection: a population-based study. Inflamm Bowel Dis 2014;20:1316-23.

79. Nguyen GC, Bernstein CN, Bitton A, et al. Consensus statements on the risk, prevention, and treatment of venous thromboembolism in inflammatory bowel disease: Canadian Association of Gastroenterology. Gastroenterology 2014;146:835.e6-48.e6.

80. Nylund CM, Goudie A, Garza JM, et al. Venous thrombotic events in hospitalized children and adolescents with inflammatory bowel disease. J Pediatr Gastroenterol Nutr 2013;56:485-91.

81. Kappelman MD, Horvath-Puho E, Sandler RS, et al. Thromboembolic risk among Danish children and adults with inflammatory bowel diseases: a population-based nationwide study. Gut 2011;60:937-43. 
82. Jackson PC, Morgan JM. Perioperative thromboprophylaxis in children: development of a guideline for management. Paediatr Anaesth 2008; $18: 478-87$.

83. Subramanian V, Saxena S, Kang JY, et al. Preoperative steroid use and risk of postoperative complications in patients with inflammatory bowel disease undergoing abdominal surgery. Am J Gastroenterol 2008; 103:2373-81.

84. Sharma A, Chinn BT. Preoperative optimization of crohn disease. Clin Colon Rectal Surg 2013;26:75-9.

85. Nguyen GC, Elnahas A, Jackson TD. The impact of preoperative steroid use on short-term outcomes following surgery for inflammatory bowel disease. J Crohns Colitis 2014;8:1661-7.

86. Lichtenstein GR, Feagan BG, Cohen RD, et al. Serious infections and mortality in association with therapies for Crohn's disease: TREAT registry. Clin Gastroenterol Hepatol 2006;4:621-30.

87. Lichtenstein GR, Feagan BG, Cohen RD, et al. Serious infection and mortality in patients with Crohn's disease: more than 5 years of followup in the TREAT registry. Am J Gastroenterol 2012;107:1409-22.

88. Sidoroff M, Kolho KL. Screening for adrenal suppression in children with inflammatory bowel disease discontinuing glucocorticoid therapy. BMC Gastroenterol 2014;14:51.

89. Krasner AS. Glucocorticoid-induced adrenal insufficiency. JAMA 1999;282:671-6.

90. Wang AS, Armstrong EJ, Armstrong AW. Corticosteroids and wound healing: clinical considerations in the perioperative period. Am J Surg 2013;206:410-7.

91. Kumar A, Auron M, Aneja A, et al. Inflammatory bowel disease: perioperative pharmacological considerations. Mayo Clin Proc 2011;86:748-57.

92. Aberra FN, Lewis JD, Hass D, et al. Corticosteroids and immunomodulators: postoperative infectious complication risk in inflammatory bowel disease patients. Gastroenterology 2003;125:320-7.

93. Colombel JF, Loftus EV Jr, Tremaine WJ, et al. Early postoperative complications are not increased in patients with Crohn's disease treated perioperatively with infliximab or immunosuppressive therapy. Am J Gastroenterol 2004;99:878-83.

94. Canedo J, Lee SH, Pinto R, et al. Surgical resection in Crohn's disease: is immunosuppressive medication associated with higher postoperative infection rates? Colorectal Dis 2011;13:1294-8.

95. Tay GS, Binion DG, Eastwood D, et al. Multivariate analysis suggests improved perioperative outcome in Crohn's disease patients receiving immunomodulator therapy after segmental resection and/or strictureplasty. Surgery 2003;134:565-72.

96. Myrelid P, Olaison G, Sjodahl R, et al. Thiopurine therapy is associated with postoperative intra-abdominal septic complications in abdominal surgery for Crohn's disease. Dis Colon Rectum 2009;52:1387-94.

97. Heldmann F, Braun J. Perioperative use of methotrexate. Clin Exp Rheumatol 2010;28(5 suppl 61):S110-3.

98. Schaufler C, Lerer T, Campbell B, et al. Preoperative immunosuppression is not associated with increased postoperative complications following colectomy in children with colitis. J Pediatr Gastroenterol Nutr 2012;55:421-4.

99. Yang ZP, Hong L, Wu Q, et al. Preoperative infliximab use and postoperative complications in Crohn's disease: a systematic review and meta-analysis. Int J Surg 2014;12:224-30.

100. Hu D, Ren J, Wang G, et al. Exclusive enteral nutritional therapy can relieve inflammatory bowel stricture in Crohn's disease. J Clin Gastroenterol 2014;48:790-5.

101. Yamamoto T, Allan RN, Keighley MR. Risk factors for intra-abdominal sepsis after surgery in Crohn's disease. Dis Colon Rectum 2000;43:1141-5.

102. Alves A, Panis Y, Bouhnik Y, et al. Risk factors for intra-abdominal septic complications after a first ileocecal resection for Crohn's disease: a multivariate analysis in 161 consecutive patients. Dis Colon Rectum 2007;50:331-6.

103. Jacobson S. Early postoperative complications in patients with Crohn's disease given and not given preoperative total parenteral nutrition. Scand J Gastroenterol 2012;47:170-7.

104. Lindor KD, Fleming CR, Ilstrup DM. Preoperative nutritional status and other factors that influence surgical outcome in patients with Crohn's disease. Mayo Clin Proc 1985;60:393-6.
105. Yao GX, Wang XR, Jiang ZM, et al. Role of perioperative parenteral nutrition in severely malnourished patients with Crohn's disease. World J Gastroenterol 2005;11:5732-4.

106. Blair GK, Yaman M, Wesson DE. Preoperative home elemental enteral nutrition in complicated Crohn's disease. J Pediatr Surg 1986;21:76971.

107. Zerbib P, Koriche D, Truant S, et al. Pre-operative management is associated with low rate of post-operative morbidity in penetrating Crohn's disease. Aliment Pharmacol Ther 2010;32:459-65.

108. Ban L, Tata LJ, Humes DJ, et al. Decreased fertility rates in 9639 women diagnosed with inflammatory bowel disease: a United Kingdom population-based cohort study. Aliment Pharmacol Ther 2015;42:855-66.

109. Mayberry JF, Weterman IT. European survey of fertility and pregnancy in women with Crohn's disease: a case control study by European collaborative group. Gut 1986;27:821-5.

110. Tekkis PP, Purkayastha S, Lanitis S, et al. A comparison of segmental vs subtotal/total colectomy for colonic Crohn's disease: a meta-analysis. Colorectal Dis 2006;8:82-90.

111. Ozdemir Y, Kiran RP, Erem HH, et al. Functional outcomes and complications after restorative proctocolectomy and ileal pouch anal anastomosis in the pediatric population. J Am Coll Surg 2014; 218:328-35.

112. Brown CJ, Maclean AR, Cohen Z, et al. Crohn's disease and indeterminate colitis and the ileal pouch-anal anastomosis: outcomes and patterns of failure. Dis Colon Rectum 2005;48:1542-9.

113. Melton GB, Fazio VW, Kiran RP, et al. Long-term outcomes with ileal pouch-anal anastomosis and Crohn's disease: pouch retention and implications of delayed diagnosis. Ann Surg 2008;248:608-16.

114. Sagar PM, Dozois RR, Wolff BG. Long-term results of ileal pouchanal anastomosis in patients with Crohn's disease. Dis Colon Rectum 1996;39:893-8.

115. Grucela AL, Bauer JJ, Gorfine SR, et al. Outcome and long-term function of restorative proctocolectomy for Crohn's disease: comparison to patients with ulcerative colitis. Colorectal Dis 2011;13:426-30.

116. Reese GE, Lovegrove RE, Tilney HS, et al. The effect of Crohn's disease on outcomes after restorative proctocolectomy. Dis Colon Rectum 2007;50:239-50.

117. Le Q, Melmed G, Dubinsky M, et al. Surgical outcome of ileal pouchanal anastomosis when used intentionally for well-defined Crohn's disease. Inflamm Bowel Dis 2013;19:30-6.

118. Shen B, Patel S, Lian L. Natural history of Crohn's disease in patients who underwent intentional restorative proctocolectomy with ileal pouch-anal anastomosis. Aliment Pharmacol Ther 2010;31:745-53.

119. Ahmed M, Jenkins HR. Vitamin B-12 in Crohn's disease patients with small bowel surgery. Arch Dis Child 2004;89:293.

120. Lee YK, Kim HS, Kang HJ. Holotranscobalamin as an indicator of vitamin B12 deficiency in gastrectomized patients. Ann Clin Lab Sci 2009;39:361-6.

121. Battat R, Kopylov U, Szilagyi A, et al. Vitamin B12 deficiency in inflammatory bowel disease: prevalence, risk factors, evaluation, and management. Inflamm Bowel Dis 2014;20:1120-8.

122. Smith MJ, Cherian P, Raju GS, et al. Bile acid malabsorption in persistent diarrhoea. J R Coll Physicians Lond 2000;34:448-51.

123. Vitek L, Carey MC. Enterohepatic cycling of bilirubin as a cause of 'black' pigment gallstones in adult life. Eur $J$ Clin Invest 2003;33:799-810.

124. Gothe F, Beigel F, Rust C, et al. Bile acid malabsorption assessed by 7 alpha-hydroxy-4-cholesten-3-one in pediatric inflammatory bowel disease: correlation to clinical and laboratory findings. J Crohns Colitis 2014;8:1072-8.

125. Borghede MK, Schlutter JM, Agnholt JS, et al. Bile acid malabsorption investigated by selenium-75-homocholic acid taurine ((75)SeHCAT) scans: causes and treatment responses to cholestyramine in 298 patients with chronic watery diarrhoea. Eur J Intern Med 2011;22: e137-40.

126. Camilleri M, Nadeau A, Tremaine WJ, et al. Measurement of serum 7alpha-hydroxy-4-cholesten-3-one (or 7alphaC4), a surrogate test for bile acid malabsorption in health, ileal disease and irritable bowel syndrome using liquid chromatography-tandem mass spectrometry. Neurogastroenterol Motil 2009;21:734-43. 
127. Lenicek M, Duricova D, Komarek V, et al. Bile acid malabsorption in inflammatory bowel disease: assessment by serum markers. Inflamm Bowel Dis 2011;17:1322-7.

128. Gothe F, Beigel F, Rust C, et al. Bile acid malabsorption assessed by 7 alpha-hydroxy-4-cholesten-3-one in pediatric inflammatory bowel disease: correlation to clinical and laboratory findings. J Crohns Colitis 2014;8:1072-8.

129. Akobeng AK, Suresh-Babu MV, Firth D, et al. Quality of life in children with Crohn's disease: a pilot study. J Pediatr Gastroenterol Nutr 1999;28:S37-9.

130. Rabbett H, Elbadri A, Thwaites R, et al. Quality of life in children with Crohn's disease. J Pediatr Gastroenterol Nutr 1996;23:528-33.

131. Andersson P, Olaison G, Bendtsen P, et al. Health related quality of life in Crohn's proctocolitis does not differ from a general population when in remission. Colorectal Dis 2003;5:56-62.

132. Dutta S, Rothenberg SS, Chang J, et al. Total intracorporeal laparoscopic resection of Crohn's disease. J Pediatr Surg 2003;38:717-9.

133. Bamford R, Hay A, Kumar D. Resection leads to less recurrence than strictureplasty in a paediatric population with obstructive Crohn's disease. Surg Res Pract 2014;2014:709045.

134. Simillis C, Purkayastha S, Yamamoto T, et al. A meta-analysis comparing conventional end-to-end anastomosis vs. other anastomotic configurations after resection in Crohn's disease. Dis Colon Rectum 2007;50:1674-87.

135. Yamamoto T, Watanabe T. Surgery for luminal Crohn's disease. World J Gastroenterol 2014;20:78-90.

136. Stocchi L, Milsom JW, Fazio VW. Long-term outcomes of laparoscopic versus open ileocolic resection for Crohn's disease: follow-up of a prospective randomized trial. Surgery 2008;144:622-7.

137. Eshuis EJ, Slors JF, Stokkers PC, et al. Long-term outcomes following laparoscopically assisted versus open ileocolic resection for Crohn's disease. Br J Surg 2010;97:563-8.

138. Watanabe K, Sasaki I, Fukushima K, et al. Long-term incidence and characteristics of intestinal failure in Crohn's disease: a multicenter study. J Gastroenterol 2014;49:231-8.

139. Yamamoto T, Allan RN, Keighley MR. Long-term outcome of surgical management for diffuse jejunoileal Crohn's disease. Surgery 2001;129:96-102.

140. Uchino M, Ikeuchi H, Bando T, et al. Risk factors for short bowel syndrome in patients with Crohn's disease. Surg Today 2012;42:44752.

141. Ambe R, Campbell L, Cagir B. A comprehensive review of strictureplasty techniques in Crohn's disease: types, indications, comparisons, and safety. J Gastrointest Surg 2012;16:209-17.

142. Shaffer VO, Wexner SD. Surgical management of Crohn's disease Langenbecks Arch Surg 2013;398:13-27.

143. Wei L, MacDonald T, Shimi S. Association between appendicectomy in females and subsequent pregnancy rate: a cohort study. Fertil Steril 2012;98:401-5.

144. Rutgeerts P, Van Assche G. What is the role of endoscopy in the postoperative management of Crohn's disease? Inflamm Bowel Dis 2008;14(suppl 2):S179-80.

145. Walters TD, Steinhart AH, Bernstein CN, et al. Validating Crohn's disease activity indices for use in assessing postoperative recurrence. Inflamm Bowel Dis 2011;17:1547-56.

146. Sokol H, Polin V, Lavergne-Slove A, et al. Plexitis as a predictive factor of early postoperative clinical recurrence in Crohn's disease. Gut 2009;58:1218-25.

147. Rutgeerts P, Geboes K, Vantrappen G, et al. Natural history of recurrent Crohn's disease at the ileocolonic anastomosis after curative surgery. Gut 1984;25:665-72.

148. Spinelli A, Sacchi M, Fiorino G, et al. Risk of postoperative recurrence and postoperative management of Crohn's disease. World J Gastroenterol 2011;17:3213-9.

149. Cho SM, Cho SW, Regueiro M. Postoperative management of crohn disease. Gastroenterol Clin North Am 2009;38:753-62.

150. De Cruz P, Kamm MA, Prideaux L, et al. Postoperative recurrent luminal Crohn's disease: a systematic review. Inflamm Bowel Dis 2012;18:758-77.

151. Rutgeerts P, Geboes K, Vantrappen G, et al. Predictability of the postoperative course of Crohn's disease. Gastroenterology 1990;99: 956-63.
152. Sandborn WJ, Feagan BG, Hanauer SB, et al. A review of activity indices and efficacy endpoints for clinical trials of medical therapy in adults with Crohn's disease. Gastroenterology 2002;122:512-30.

153. De Cruz P, Kamm MA, Hamilton AL, et al. Crohn's disease management after intestinal resection: a randomised trial. Lancet 2015; 385:1046.

154. Orlando A, Mocciaro F, Renna S, et al. Early post-operative endoscopic recurrence in Crohn's disease patients: data from an Italian Group for the study of inflammatory bowel disease (IG-IBD) study on a large prospective multicenter cohort. J Crohns Colitis 2014;8:121721.

155. Regueiro M, Schraut W, Baidoo L, et al. Infliximab prevents Crohn's disease recurrence after ileal resection. Gastroenterology 2009;136: 441.e1-50.e1.

156. Orlando A, Modesto I, Castiglione F, et al. The role of calprotectin in predicting endoscopic post-surgical recurrence in asymptomatic Crohn's disease: a comparison with ultrasound. Eur Rev Med Pharmacol Sci 2006;10:17-22.

157. Lamb CA, Mohiuddin MK, Gicquel J, et al. Faecal calprotectin or lactoferrin can identify postoperative recurrence in Crohn's disease. $\mathrm{Br}$ J Surg 2009;96:663-74.

158. De Cruz P, Bernardi MP, Kamm MA, et al. Postoperative recurrence of Crohn's disease: impact of endoscopic monitoring and treatment stepup. Colorectal Dis 2013;15:187-97.

159. Wright EK, Kamm MA, De Cruz P, et al. Measurement of fecal calprotectin improves monitoring and detection of recurrence of Crohn's disease after surgery. Gastroenterology 2015;148:938-47.

160. Boschetti G, Laidet M, Moussata D, et al. Levels of fecal calprotectin are associated with the severity of postoperative endoscopic recurrence in asymptomatic patients with Crohn's disease. Am J Gastroenterol 2015;110:865-72.

161. Hukkinen M, Pakarinen MP, Merras-Salmio L, et al. Fecal calprotectin in the prediction of postoperative recurrence of Crohn's disease in children and adolescents. J Pediatr Surg 2016;51:1467-72.

162. Biancone L, Fiori R, Tosti C, et al. Virtual colonoscopy compared with conventional colonoscopy for stricturing postoperative recurrence in Crohn's disease. Inflamm Bowel Dis 2003;9:343-50.

163. Koilakou S, Sailer J, Peloschek P, et al. Endoscopy and MR enteroclysis: equivalent tools in predicting clinical recurrence in patients with Crohn's disease after ileocolic resection. Inflamm Bowel Dis 2010;16:198-203.

164. Doherty G, Bennett G, Patil S, et al. Interventions for prevention of post-operative recurrence of Crohn's disease. Cochrane Database Syst Rev 2009;4:CD006873.

165. Papay P, Reinisch W, Ho E, et al. The impact of thiopurines on the risk of surgical recurrence in patients with Crohn's disease after first intestinal surgery. Am J Gastroenterol 2010;105:1158-64.

166. Domenech E, Manosa M, Bernal I, et al. Impact of azathioprine on the prevention of postoperative Crohn's disease recurrence: results of a prospective, observational, long-term follow-up study. Inflamm Bowel Dis 2008;14:508-13.

167. Peyrin-Biroulet L, Deltenre P, Ardizzone S, et al. Azathioprine and 6mercaptopurine for the prevention of postoperative recurrence in Crohn's disease: a meta-analysis. Am J Gastroenterol 2009;104: 2089-96.

168. Jones GR, Kennedy NA, Lees CW, et al. Systematic review: the use of thiopurines or anti-TNF in post-operative Crohn's disease maintenance-progress and prospects. Aliment Pharmacol Ther 2014;39: $1253-65$.

169. Hanauer SB, Korelitz BI, Rutgeerts P, et al. Postoperative maintenance of Crohn's disease remission with 6-mercaptopurine, mesalamine, or placebo: a 2-year trial. Gastroenterology 2004;127:723-9.

170. Gordon M, Taylor K, Akobeng AK, et al. Azathioprine and 6-mercaptopurine for maintenance of surgically-induced remission in Crohn's disease. Cochrane Database Syst Rev 2014;8:CD010233.

171. D'Haens GR, Vermeire S, Van Assche G, et al. Therapy of metronidazole with azathioprine to prevent postoperative recurrence of Crohn's disease: a controlled randomized trial. Gastroenterology 2008; 135:1123-9.

172. Shen FC, Zhang HJ, Zhao XD, et al. Purine analogues compared with mesalamine or 5-ASA for the prevention of postoperative recurrence in Crohn's disease: a meta-analysis. Int J Clin Pract 2012;66:758-66. 
173. Reinisch W, Angelberger S, Petritsch W, et al. Azathioprine versus mesalazine for prevention of postoperative clinical recurrence in patients with Crohn's disease with endoscopic recurrence: efficacy and safety results of a randomised, double-blind, double-dummy, multicentre trial. Gut 2010;59:752-9.

174. Ardizzone S, Maconi G, Sampietro GM, et al. Azathioprine and mesalamine for prevention of relapse after conservative surgery for Crohn's disease. Gastroenterology 2004;127:730-40.

175. Regueiro M, Feagan BG, Zou B, et al. Infliximab reduces endoscopic, but not clinical, recurrence of Crohn's disease after ileocolonic resection. Gastroenterology 2016;150:1568-78.

176. Sorrentino D, Paviotti A, Terrosu G, et al. Low-dose maintenance therapy with infliximab prevents postsurgical recurrence of Crohn's disease. Clin Gastroenterol Hepatol 2010;8:591.e1-9.e1.

177. McLeod RS, Wolff BG, Steinhart AH, et al. Prophylactic mesalamine treatment decreases postoperative recurrence of Crohn's disease. Gastroenterology 1995;109:404-13.

178. Brignola C, Cottone M, Pera A, et al. Mesalamine in the prevention of endoscopic recurrence after intestinal resection for Crohn's disease. Italian Cooperative Study Group. Gastroenterology 1995;108:345-9.

179. Lochs H, Mayer M, Fleig WE, et al. Prophylaxis of postoperative relapse in Crohn's disease with mesalamine: European Cooperative Crohn's Disease Study VI. Gastroenterology 2000;118:264-73.

180. Caprilli R, Cottone M, Tonelli F, et al. Two mesalazine regimens in the prevention of the post-operative recurrence of Crohn's disease: a pragmatic, double-blind, randomized controlled trial. Aliment Pharmacol Ther 2003;17:517-23.

181. Florent C, Cortot A, Quandale P, et al. Placebo-controlled clinical trial of mesalazine in the prevention of early endoscopic recurrences after resection for Crohn's disease. Groupe d'Etudes Therapeutiques des Affections Inflammatoires Digestives (GETAID). Eur J Gastroenterol Hepatol 1996;8:229-33.

182. Manosa M, Cabre E, Bernal I, et al. Addition of metronidazole to azathioprine for the prevention of postoperative recurrence of Crohn's disease: a randomized, double-blind, placebo-controlled trial. Inflamm Bowel Dis 2013;19:1889-95.

183. Rutgeerts P, Hiele M, Geboes K, et al. Controlled trial of metronidazole treatment for prevention of Crohn's recurrence after ileal resection. Gastroenterology 1995;108:1617-21.

184. Rutgeerts P, Van Assche G, Vermeire S, et al. Ornidazole for prophylaxis of postoperative Crohn's disease recurrence: a randomized, doubleblind, placebo-controlled trial. Gastroenterology 2005;128:856-61.

185. Herfarth HH, Katz JA, Hanauer SB, et al. Ciprofloxacin for the prevention of postoperative recurrence in patients with Crohn's disease: a randomized, double-blind, placebo-controlled pilot study. Inflamm Bowel Dis 2013;19:1073-9.

186. Ewe K, Bottger T, Buhr HJ, et al. Low-dose budesonide treatment for prevention of postoperative recurrence of Crohn's disease: a multicentre randomized placebo-controlled trial. German Budesonide Study Group. Eur J Gastroenterol Hepatol 1999;11:277-82.

187. Prantera C, Scribano ML, Falasco G, et al. Ineffectiveness of probiotics in preventing recurrence after curative resection for Crohn's disease: a randomised controlled trial with Lactobacillus GG. Gut 2002;51:4059.

188. Marteau P, Lemann M, Seksik P, et al. Ineffectiveness of Lactobacillus johnsonii LA1 for prophylaxis of postoperative recurrence in Crohn's disease: a randomised, double blind, placebo controlled GETAID trial. Gut 2006;55:842-7.

189. Van Gossum A, Dewit O, Louis E, et al. Multicenter randomizedcontrolled clinical trial of probiotics (Lactobacillus johnsonii, LA1) on early endoscopic recurrence of Crohn's disease after lleo-caecal resection. Inflamm Bowel Dis 2007;13:135-42.

190. Chermesh I, Tamir A, Reshef R, et al. Failure of Synbiotic 2000 to prevent postoperative recurrence of Crohn's disease. Dig Dis Sci 2007;52:385-9.

191. Hellers G, Cortot A, Jewell D, et al. Oral budesonide for prevention of postsurgical recurrence in Crohn's disease. The IOIBD Budesonide Study Group. Gastroenterology 1999;116:294-300.

192. Yamamoto T, Nakahigashi M, Umegae S, et al. Impact of long-term enteral nutrition on clinical and endoscopic recurrence after resection for Crohn's disease: a prospective, non-randomized, parallel, controlled study. Aliment Pharmacol Ther 2007;25:67-72.
193. Yamamoto T, Shiraki M, Nakahigashi M, et al. Enteral nutrition to suppress postoperative Crohn's disease recurrence: a five-year prospective cohort study. Int J Colorectal Dis 2013;28:335-40.

194. Esaki M, Matsumoto T, Hizawa K, et al. Preventive effect of nutritional therapy against postoperative recurrence of Crohn disease, with reference to findings determined by intra-operative enteroscopy. Scand $J$ Gastroenterol 2005;40:1431-7.

195. Hojsak I, Kolacek S, Hansen LF, et al. Long-term outcomes after elective ileocecal resection in children with active localized Crohn's disease-a multicenter European study. J Pediatr Surg 2015;50:1630_5.

196. Duncan H, Buchanan E, Cardigan T, et al. A retrospective study showing maintenance treatment options for paediatric $\mathrm{CD}$ in the first year following diagnosis after induction of remission with EEN: supplemental enteral nutrition is better than nothing! BMC Gastroenterol 2014;14:50.

197. Konno M, Takahashi M, Toita N, et al. Long-term therapeutic effectiveness of maintenance enteral nutrition for Crohn's disease. Pediatr Int 2015;57:276-80.

198. Qiu Y, Mao R, Chen BL, et al. Fecal calprotectin for evaluating postoperative recurrence of Crohn's disease: a meta-analysis of prospective studies. Inflamm Bowel Dis 2015;21:315-22.

199. Lopes S, Andrade P, Afonso J, et al. Correlation between calprotectin and modified Rutgeerts score. Inflamm Bowel Dis 2016;22:2173-81.

200. Bordeianou L, Stein SL, Ho VP, et al. Immediate versus tailored prophylaxis to prevent symptomatic recurrences after surgery for ileocecal Crohn's disease? Surgery 2011;149:72-8.

201. Baudry C, Pariente B, Lourenco N, et al. Tailored treatment according to early post-surgery colonoscopy reduces clinical recurrence in Crohn's disease: a retrospective study. Dig Liver Dis 2014;46:887-92.

202. Keighley MR, Allan RN. Current status and influence of operation on perianal Crohn's disease. Int J Colorectal Dis 1986;1:104-7.

203. Schwartz DA, Loftus EV Jr, Tremaine WJ, et al. The natural history of fistulizing Crohn's disease in Olmsted County, Minnesota. Gastroenterology 2002;122:875-80.

204. Hellers G, Bergstrand O, Ewerth S, et al. Occurrence and outcome after primary treatment of anal fistulae in Crohn's disease. Gut 1980;21: 525-7.

205. Keljo DJ, Markowitz J, Langton C, et al. Course and treatment of perianal disease in children newly diagnosed with Crohn's disease. Inflamm Bowel Dis 2009;15:383-7.

206. Griffiths AM. Specificities of inflammatory bowel disease in childhood. Best Pract Res Clin Gastroenterol 2004;18:509-23.

207. de Zoeten EF, Pasternak BA, Mattei P, et al. Diagnosis and treatment of perianal Crohn disease: NASPGHAN clinical report and consensus statement. J Pediatr Gastroenterol Nutr 2013;57:401-12.

208. Muller KE, Lakatos PL, Arato A, et al. Incidence, Paris classification, and follow-up in a nationwide incident cohort of pediatric patients with inflammatory bowel disease. J Pediatr Gastroenterol Nutr 2013;57: 576-82.

209. Parks AG, Gordon PH, Hardcastle JD. A classification of fistula-inano. Br J Surg 1976;63:1-12.

210. Bell SJ, Williams AB, Wiesel P, et al. The clinical course of fistulating Crohn's disease. Aliment Pharmacol Ther 2003;17:1145-51.

211. Orlando A, Armuzzi A, Papi C, et al. The Italian Society of Gastroenterology (SIGE) and the Italian Group for the study of Inflammatory Bowel Disease (IG-IBD) Clinical Practice Guidelines: the use of tumor necrosis factor-alpha antagonist therapy in inflammatory bowel disease. Dig Liver Dis 2011;43:1-20.

212. van AG, Dignass A, Reinisch W, et al. The second European evidencebased consensus on the diagnosis and management of Crohn's disease: special situations. J Crohns Colitis 2010;4:63-101.

213. Haggett PJ, Moore NR, Shearman JD, et al. Pelvic and perineal complications of Crohn's disease: assessment using magnetic resonance imaging. Gut 1995;36:407-10.

214. Tang LY, Rawsthorne P, Bernstein CN. Are perineal and luminal fistulas associated in Crohn's disease? A population-based study. Clin Gastroenterol Hepatol 2006;4:1130-4.

215. Hammer MR, Dillman JR, Smith EA, et al. Magnetic resonance imaging of perianal and perineal crohn disease in children and adolescents. Magn Reson Imaging Clin N Am 2013;21:813-28. 
216. Kulkarni S, Gomara R, Reeves-Garcia J, et al. MRI-based score helps in assessing the severity and in follow-up of pediatric patients with perianal Crohn disease. J Pediatr Gastroenterol Nutr 2014;58:252-7.

217. Shenoy-Bhangle A, Nimkin K, Goldner D, et al. MRI predictors of treatment response for perianal fistulizing Crohn disease in children and young adults. Pediatr Radiol 2014;44:23-9.

218. Essary B, Kim J, Anupindi S, et al. Pelvic MRI in children with Crohn disease and suspected perianal involvement. Pediatr Radiol 2007;37: 201-8.

219. Skalej M, Makowiec F, Weinlich M, et al. Magnetic resonance imaging in perianal Crohn's disease. Dtsch Med Wochenschr 1993;118:1791-6.

220. Rosen MJ, Moulton DE, Koyama T, et al. Endoscopic ultrasound to guide the combined medical and surgical management of pediatric perianal Crohn's disease. Inflamm Bowel Dis 2010;16:461-8.

221. Markowitz J, Grancher K, Rosa J, et al. Highly destructive perianal disease in children with Crohn's disease. J Pediatr Gastroenterol Nutr 1995;21:149-53.

222. Casson DH, Eltumi M, Tomlin S, et al. Topical tacrolimus may be effective in the treatment of oral and perineal Crohn's disease. Gut 2000;47:436-40.

223. Eradi B, Sandhu BK, Spray C, et al. Highly destructive perianal crohn disease. J Pediatr Gastroenterol Nutr 2005;41:667-9.

224. Shetty AK, Udall J Jr. Schmidt-Sommerfeld E Highly destructive perianal Crohn's disease. J Natl Med Assoc 1998;90:491-2.

225. Klinger A, Schursky M, Rosh J, et al. Combination biological and surgical therapy in an adolescent presenting with highly destructive perianal Crohn disease. J Pediatr Gastroenterol Nutr 2010;51:784-6.

226. Tozer PJ, Burling D, Gupta A, et al. Review article: medical, surgical and radiological management of perianal Crohn's fistulas. Aliment Pharmacol Ther 2011;33:5-22.

227. O'Brien JJ, Bayless TM, Bayless JA. Use of azathioprine or 6mercaptopurine in the treatment of Crohn's disease. Gastroenterology 1991;101:39-46.

228. Sandborn WJ. A critical review of cyclosporine therapy in inflammatory bowel disease. Inflamm Bowel Dis 1995;1:48-63.

229. Sandborn WJ. Preliminary report on the use of oral tacrolimus (FK506) in the treatment of complicated proximal small bowel and fistulizing Crohn's disease. Am J Gastroenterol 1997;92:876-9.

230. Present DH, Rutgeerts P, Targan S, et al. Infliximab for the treatment of fistulas in patients with Crohn's disease. N Engl J Med 1999;340: $1398-405$.

231. Kouklakis G, Efremidou EI, Zezos P, et al. Adalimumab-an effective and promising treatment for patients with fistulizing Crohn's disease: a case series. J Med Case Rep 2011;5:109.

232. Colombel JF, Schwartz DA, Sandborn WJ, et al. Adalimumab for the treatment of fistulas in patients with Crohn's disease. Gut 2009;58:940-8

233. Sandborn WJ, Rutgeerts P, Enns R, et al. Adalimumab induction therapy for Crohn disease previously treated with infliximab: a randomized trial. Ann Intern Med 2007;146:829-38.

234. Peyrin-Biroulet L, Laclotte C, Bigard MA. Adalimumab maintenance therapy for Crohn's disease with intolerance or lost response to infliximab: an open-label study. Aliment Pharmacol Ther 2007;25: 675-80.

235. Sands BE, Anderson FH, Bernstein CN, et al. Infliximab maintenance therapy for fistulizing Crohn's disease. $N$ Engl J Med 2004;350: 876-85.
236. Sands BE, Blank MA, Patel K, et al. Long-term treatment of rectovaginal fistulas in Crohn's disease: response to infliximab in the ACCENT II Study. Clin Gastroenterol Hepatol 2004;2: 912-20.

237. Crandall W, Hyams J, Kugathasan S, et al. Infliximab therapy in children with concurrent perianal Crohn disease: observations from REACH. J Pediatr Gastroenterol Nutr 2009;49:183-90.

238. de Ridder L, Escher JC, Bouquet J, et al. Infliximab therapy in 30 patients with refractory pediatric crohn disease with and without fistulas in The Netherlands. J Pediatr Gastroenterol Nutr 2004;39: $46-52$.

239. Kim MJ, Lee JS, Lee JH, et al. Infliximab therapy in children with Crohn's disease: a one-year evaluation of efficacy comparing 'topdown' and 'step-up' strategies. Acta Paediatr 2011;100:451-5.

240. Gaertner WB, Decanini A, Mellgren A, et al. Does infliximab infusion impact results of operative treatment for Crohn's perianal fistulas? Dis Colon Rectum 2007;50:1754-60.

241. van der Hagen SJ, Baeten CG, Soeters PB, et al. Anti-TNF-alpha (infliximab) used as induction treatment in case of active proctitis in a multistep strategy followed by definitive surgery of complex anal fistulas in Crohn's disease: a preliminary report. Dis Colon Rectum 2005;48:758-67.

242. Hyder SA, Travis SP, Jewell DP, et al. Fistulating anal Crohn's disease: results of combined surgical and infliximab treatment. Dis Colon Rectum 2006;49:1837-41.

243. Topstad DR, Panaccione R, Heine JA, et al. Combined seton placement, infliximab infusion, and maintenance immunosuppressives improve healing rate in fistulizing anorectal Crohn's disease: a single center experience. Dis Colon Rectum 2003;46:577-83.

244. Hukkinen M, Pakarinen MP, Piekkala M, et al. Treatment of complex perianal fistulas with seton and infliximab in adolescents with Crohn's disease. J Crohns Colitis 2014;8:756-62.

245. Poggioli G, Laureti S, Pierangeli F, et al. Local injection of Infliximab for the treatment of perianal Crohn's disease. Dis Colon Rectum 2005;48:768-74.

246. de la Portilla F, Alba F, Garcia-Olmo D, et al. Expanded allogeneic adipose-derived stem cells (eASCs) for the treatment of complex perianal fistula in Crohn's disease: results from a multicenter phase I/IIa clinical trial. Int J Colorectal Dis 2013;28:313-23.

247. Bellaiche M, Besnard M, Faure C, et al. Perineal lesions in childhood Crohn disease. Arch Pediatr 1998;5:3-8.

248. Tozer PJ, Balmforth D, Kayani B, et al. Surgical management of rectovaginal fistula in a tertiary referral centre: many techniques are needed. Colorectal Dis 2013;15:871-7.

249. de la Poza G, Lopez-Sanroman A, Taxonera C, et al. Genital fistulas in female Crohn's disease patients.: clinical characteristics and response to therapy. J Crohns Colitis 2012;6:276-80.

250. Jarrar A, Church J. Advancement flap repair: a good option for complex anorectal fistulas. Dis Colon Rectum 2011;54:1537-41.

251. Champagne BJ, McGee MF. Rectovaginal fistula. Surg Clin North Am 2010;90:69-82.

252. Furst A, Schmidbauer C, Swol-Ben J, et al. Gracilis transposition for repair of recurrent anovaginal and rectovaginal fistulas in Crohn's disease. Int J Colorectal Dis 2008;23:349-53.

253. Troja A, Kase P, El-Sourani N, et al. Treatment of recurrent rectovaginal/pouch-vaginal fistulas by gracilis muscle transposition - a single center experience. J Visc Surg 2013;150:379-82. 